\title{
Effects of Plateau Air Quality and Low Oxygen Content on Platelet mtDNA Methylation and High Altitude Pulmonary Edema
}

\author{
Ziquan Liu ${ }^{1,2,3 \dagger}$, Huanhuan Cui ${ }^{1,2,3 \dagger}$, Lei Zhao ${ }^{1,2,3}$, Fucai Ma ${ }^{4}$, Yanqing $\mathrm{Liu}^{1,2,3}$, \\ Yuansen Chen ${ }^{1,2,3}$, Jiale Chen ${ }^{1,2,3}$, Yaning Jia ${ }^{1,2,3}$, Wenli $\mathrm{Li}^{1,2,3}$, Jinxia Cai ${ }^{1,2,3}$, \\ Xun $\mathrm{Bi}^{5}$, Penghui $\mathrm{Li}^{6}$, Haojun Fan ${ }^{1,2,3}$, Liqiong Guo ${ }^{1,2,3^{*}}$, Shike $\mathrm{Hou}^{1,2,3^{*}}$ \\ ${ }^{1}$ Institute of Disaster and Emergency Medicine, Tianjin University, Tianjin 300072, China \\ ${ }^{2}$ Wenzhou Safety (Emergency) Institute, Tianjin University, Wenzhou 325000, China \\ ${ }^{3}$ Tianjin Key Laboratory of Disaster Medicine Technology, Tianjin 300072, China \\ ${ }^{4}$ The Emergency Department, The Second People's Hospital of Tibet Autonomous Region, Lasa \\ 850002, China \\ ${ }^{5}$ The Military Medical Identification Department, Characteristics Medical Center of The Chinese \\ People's Armed Police Forces, Tianjin 300162, China \\ ${ }^{6}$ School of Environmental Science and Safety Engineering, Tianjin University of Technology, \\ Tianjin 300384, China
}

\section{ABSTRACT}

In 2020, the monitored AQI (Air Quality Index) in plateau-Tibet varied from 24 to 98 and averaged 48 , while the $\mathrm{PM}_{2.5}$ concentration ranged between 3.0 and $31 \mu \mathrm{g} \mathrm{m}^{-3}$ and with an average of $10 \mu \mathrm{g} \mathrm{m}^{-3}$. The plateau-Tibet, had a good air quality, but with a lower atmospheric pressure and low oxygen concentration. As the important characteristic of plateau atmospheric environment, hypobaric hypoxia $(\mathrm{HBH})$ is the key risk factor causing high altitude pulmonary edema (HAPE). It has been reported that the abnormal platelet function caused by $\mathrm{HBH}$ is an

Received: September 17, 2021 Revised: November 14, 2021 Accepted: November 23, 2021

\section{* Corresponding Authors: Liqiong Guo yingqidao@163.com Shike Hou houshike@126.com \\ ${ }^{\dagger}$ These authors contributed equally to this work}

\section{Publisher:}

Taiwan Association for Aerosol Research

ISSN: $1680-8584$ print ISSN: 2071-1409 online

(c) Copyright: The Author(s). This is an open access article distributed under the terms of the Creative Commons Attribution License (CC BY 4.0), which permits unrestricted use, distribution, and reproduction in any medium, provided the original author and source are cited. divided into control group and $\mathrm{HBH} 24,48$, and 72-hour exposed groups. A multi-functional hypoxic chamber was used to simulate HAPE model with an altitude of $6000 \mathrm{~m}$, oxygen concentration of $9.46 \%$ and partial oxygen pressure of $9.6 \mathrm{KPa}$. We measured pulmonary wet to dry (W/D) weight ratio, MT-Cox1, MT-Cox2 and MT-Cox3 methylation levels by pyrosequencing on blood samples from all rats and the levels of plasma inflammatory mediators by Luminex liquid chip technology. Results showed that the W/D ratio increased in the $\mathrm{HBH}-48 \mathrm{~h}$ and $\mathrm{HBH}-72 \mathrm{~h}$ exposed groups significantly $(p<0.05)$. The mtDNA methylation levels in all $\mathrm{HBH}$ exposed groups were lower than pre-exposure (all $p$ value $<0.05$ ). The levels of MT-Cox1, MT-Cox2_Pos2 and MT-Cox2_Pos3 methylation were correlated with W/D ratio significantly $(r=0.16-0.20, p<0.05)$. And a strong correlation was found between some inflammatory cytokines (IL 4, IL 6, IL 10 and IL 12p70) and MT-Cox2 methylation levels $(r=0.09-0.30, p<0.05)$. In conclusion, $\mathrm{HBH}$ exposures can induce alterations in platelet mtDNA methylation in HAPE, which may be related to unfavorable effects on HAPE caused by the inflammation through the regulation of inflammatory response.

Keywords: Air quality, Hypobaric hypoxia, High altitude pulmonary edema, Platelet, Mitochondrial DNA methylation

\section{INTRODUCTION}

Many studies suggested that the characteristics of atmospheric environment are pivotal in air quality and human health. The genetic landscape of all populations inhabiting nature world is shaped by the environment. People have encountered numerous novel environments with 
various temperature and climate as human populations have expanded across the world. High altitude (HA) is one of the most challenging environments humans have inhabited (Witt and Huerta-Sanchez, 2019). It is well known that atmospheric dust aerosols could affect the climate and weather systems, air quality as well as public health (Zhang et al., 2021). For example, external forces such as aerosols and greenhouse gases that change the climate on the Tibetan Plateau in response to teleconnection are elementary problems now arise (Ma et al., 2020). It has been reported that the atmosphere in Lhasa, the largest city in Tibetan Plateau, had been severely influenced by local emissions due to the current rapid urbanization and industrialization (Chen et al., 2018). However, the air quality was relatively better in Lhasa in comparison with other provincial capital cities in China (Yin et al., 2019). In addition, the air quality standards for particulate matter (PM) in HA urban areas from different countries must take temperature and pressure into account. According to health authorities, cases of asthma and allergies have increased dramatically in proportion to population growth in HA urban areas in many countries (Bravo Alvarez et al., 2013). It is necessary to understand the link between long-term air quality data with high temporal and spatial resolutions and some processes that influence air quality and correspond environmental and healthy effects (Chen et al., 2019). In this context, more and more attention has been paid to the air quality in HA environments, the effects of aerosols on regional climate change as well as the effects of these changes caused by the characteristics of HA environments on human health. As the foremost characteristic of atmospheric environment in $\mathrm{HA}$, hypobaric hypoxia $(\mathrm{HBH})$ refers to the consequent decrease of oxygen $\left(\mathrm{O}_{2}\right)$ proportion partial pressure in the inhaled air which results from lower pressure of atmosphere (Ortiz-Prado et al., 2019). It is well learned that $\mathrm{HBH}$ is the primary factor causing physiological responses to HA. Barometric pressure sets the partial pressure of alveolar $\mathrm{O}_{2}$ pressure in conjunction with alveolar ventilation, thus directly determining the partial pressure of inhaled $\mathrm{O}_{2}$ (Parati et al., 2018). The tissue hypoxia and subsequent hypoxemia trigger a considerable number of regulatory mechanisms, which in most occasions are conducive to adaptation, but sometimes it may evolve into pathological conditions such as acute mountain sickness (AMS) (Bilo et al., 2019).

High altitude pulmonary edema (HAPE), as a potentially fatal AMS, occurs within 2-4 days after reaching an altitude of $3000 \mathrm{~m}$ or above (He et al., 2017). HAPE is a severe lung injury caused by acute $\mathrm{HBH}$ and its pathogenesis is still not fully clarified, which seriously impedes the development of clinical research from preventing and treating HAPE (Jin et al., 2019). As shown in the previous studies, pulmonary hypertension (Eichstaedt et al., 2020), hypoxic contraction of pulmonary blood vessels (Swenson, 2020), increased capillary pressure (Zhang et al., 2018), blood gas barrier injury (Solaimanzadeh, 2020) and increased pulmonary vascular permeability (He et al., 2018) are the main pathophysiological factors of HAPE.

According to the reports, the degranulation of perivascular triggered by platelets would thus lead to tissue injury and inflammatory response, which are related to the pathogenesis of HAPE. Platelets that are circulating and non-nucleated cells play an important role in thrombosis, hemostasis and wound healing (Eicher et al., 2018). Function as a main site to produce terminal platelet, lung contributes substantially to nearly half of the total production of platelet biogenesis (Lefrancais et al., 2017; Demopoulos et al., 2020).

Mitochondria, as the main power supply organelle in platelets, play a crucial part in maintaining the normal structure and function of platelets (Sledz et al., 2020). Mitochondrial DNA (mtDNA), a circular double-stranded genomic DNA, exists independently in cells, which encodes 13 oxidative phosphorylation complex (OXPHOS) polypeptides located in the inner mitochondrial membrane (Sharma and Sampath, 2019). mtDNA could act as a feedback mechanism to check for changes in gene sequence in the short term because of its quick response to the stimulation of outside environment. Due to the lack of histone protection, mtDNA is vulnerable to oxidative stress damage, resulting in mtDNA methylation (Singer, 2019), which is the most extensively studied epigenetic mechanism. Epigenetics refers to the heritable changes that lead to gene expression without alteration of the original DNA sequence. There are mounting evidences indicating that epigenetic mechanisms may also contribute to regulate the replication and transcription of mtDNA (Sharma et al., 2019).

It has been suggested that epigenetic variations may interplay with platelet functions (Danese et al., 2021) and the signals from platelets were conferred epigenetic changes, including secretion of potent growth factors and upregulation of oncoproteins in circulating tumor cells, which may 
contribute to promote metastatic outgrowth, mitogenesis and angiogenesis (Tao et al., 2021). The platelet activity and apoptosis dysfunction in many diseases may be caused by mitochondrial dysfunction, such as cardiovascular disease (CVD), Alzheimer's and Parkinson's, sepsis and diabetes mellitus, which indicates that mitochondria play an indispensable role in platelet activation, metabolism, and apoptosis (Wang et al., 2017). Therefore, the epigenetic regulation of platelet mtDNA is of extraordinary significance. However, so far there have been no research in the effect of environmental HBH exposures on the levels of platelet mtDNA methylation.

Recent studies showed that hypoxia could cause mitochondrial dysfunction, which could participate in the occurrence of HAPE via multifarious pathways, such as excessive production of reactive oxygen species (ROS) (Michelakis et al., 2004), contraction of pulmonary vascular smooth muscle cells and obstacles to pulmonary water clearance (Fig. 1). Mitochondria may be the core element for HA adaptation and altitude sickness, and mtDNA mutations may be associated with the occurrence of HAPE. Previous studies have found that mitochondrial epigenetics might play an important role in HAPE apart from genetic variation (Chanana et al., 2020). ROS is mainly generated by the mitochondrial electron transport chain complexes (McElroy and Chandel, 2017). Respiratory chain complexes are made up of some subunits, most of which are encoded by nuclear genes, except for some of the subunits of complex I, III, and IV that are encoded by mtDNA and synthesized on mitochondrial ribosomes (Das et al., 2012). The main function of complex IV is OXPHOS, which is located at the end of the respiratory electron transfer chain and also known as cytochrome c oxidase (Cox) (Xiang et al., 2016). What's more, studies have reported that inflammation is a vital pathogenic feature of HAPE and a series of inflammatory factors are clearly involved in
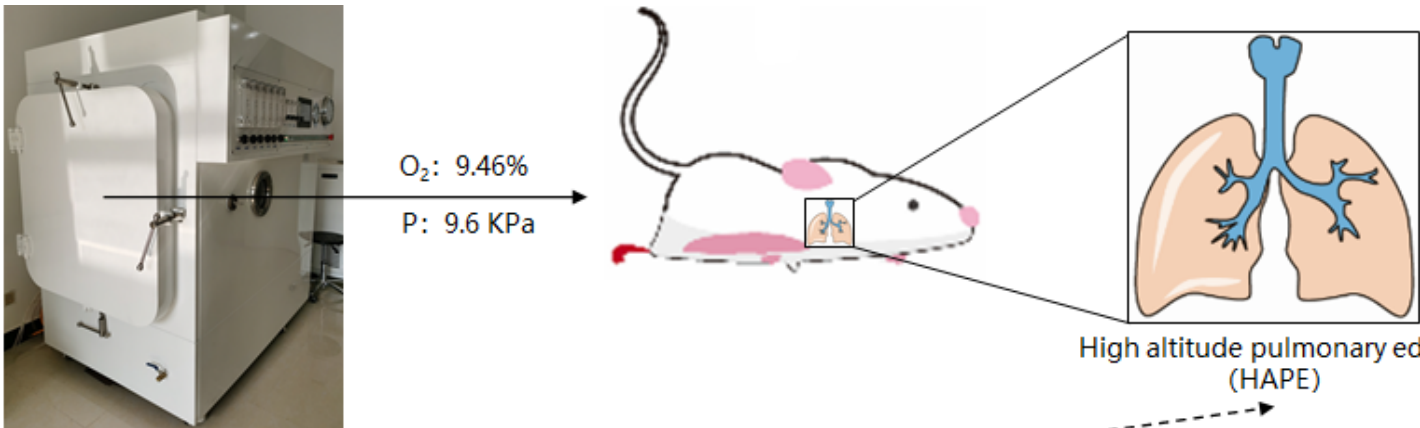

High altitude pulmonary edema (HAPE)
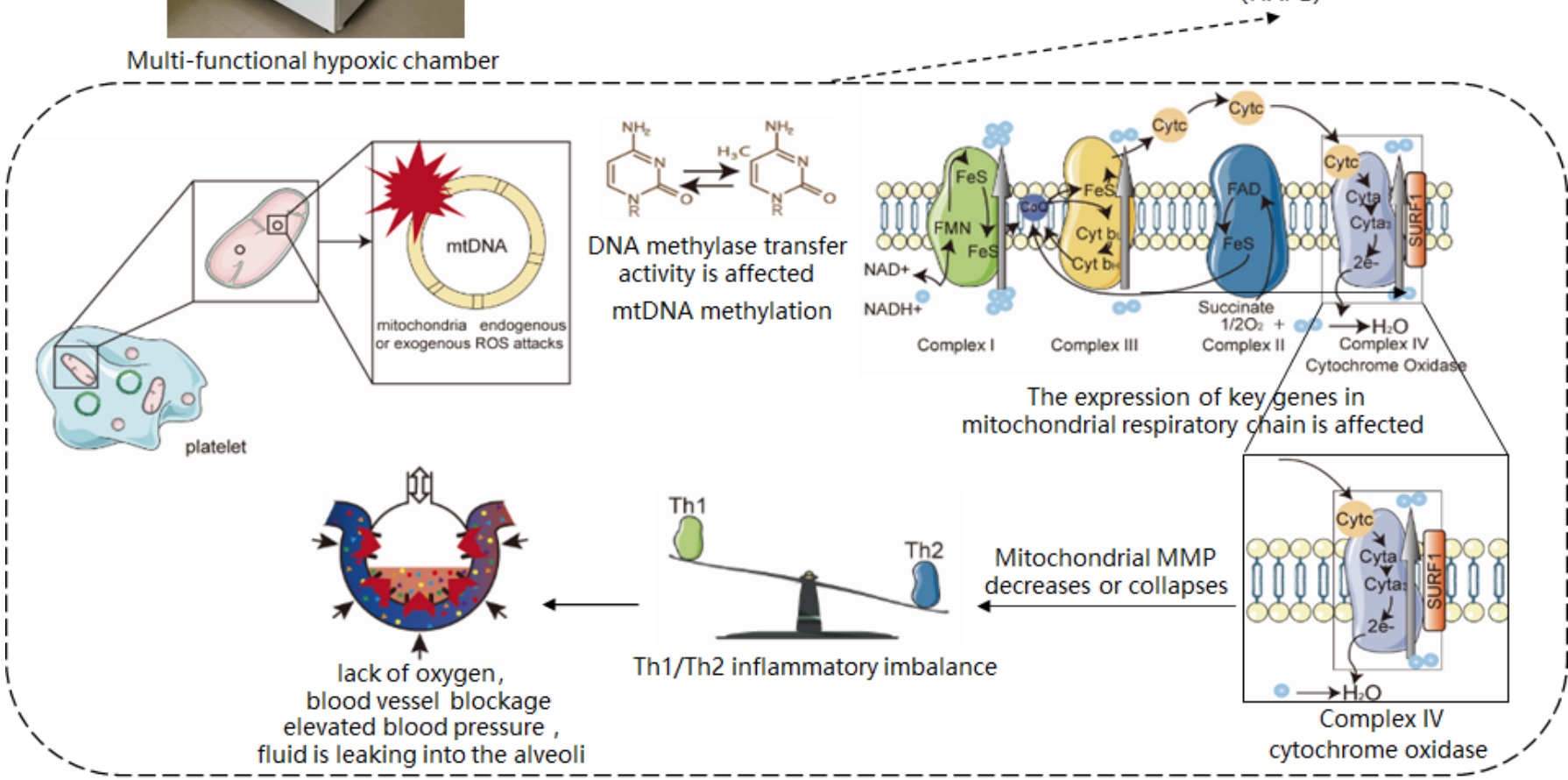

Fig. 1. Proposed conceptual model linking HBH exposure, platelet mtDNA methylation, and HAPE. PM, particulate matter; mtDNA, mitochondrial DNA; ROS, reactive oxygen species; NAD, nicotinamide-adenine dinucleotid; FMN, flavin mononucleotide; FeS, ferrous sulfide; Cyt, cytochrome; FAD, flavin adenine dinucleotide; MMP, mitochondrial membrane potential. 
the pathogenesis of HAPE (Zhou et al., 2017). It has been proven that mitochondria are both targets and regulators of inflammatory pathways, inflammatory cytokines could promote mitochondrial dysfunction (Dikalova et al., 2020).

The air quality index (AQI) and oxygen concentration in Tibet were compared and analyzed, which further proved that $\mathrm{HBH}$ was the most significant and important characteristic of the atmospheric environment in $\mathrm{HA}$. Therefore, we assumed that $\mathrm{HBH}$ could induce platelet mitochondrial dysfunction via affecting respiratory chain, which in turn trigger inflammatory response and ultimately induce lung injury or HAPE. To simulate human experiments and examine our hypothesis, 32 male Sprague-Dawley rats were placed in the multi-functional hypoxic chamber to simulate HAPE model with altitude of $6000 \mathrm{~m}$, oxygen concentration of $9.46 \%$ and partial oxygen pressure of 9.6 KPa. We quantified the levels of MT-Cox1, MT-Cox2, and MT-Cox3 methylation that encode complex IV genes in plasma platelet mtDNA in rat model of HAPE, and we detected the levels of a series of inflammatory factors in plasma. The aim of this study is to investigate the effect of plateau air quality and low oxygen content on platelet mtDNA methylation and HAPE.

\section{METHODS}

\subsection{Animals and Breeding Conditions}

SPF grade adult male SD rats, weighing $200 \pm 20 \mathrm{~g}$, were purchased from the Beijing Hua Fukang Biotechnology Co., LTD, with the production license number of SCXK (Jing) 2020-0004. All the rats were exposed to an endocellular environment at $20-26^{\circ} \mathrm{C}$ and $40-70 \%$ humidity for 2 days in advance. All the animal experiments were conducted in accordance with Tianjin Medical Experimental Animal Care guidelines, and animal protocol was approved by the Institutional Animal Care and Use Committee of Yi Shengyuan Gene Technology (Tianjin) Co., Ltd.

\subsection{Multi-functional Hypoxic Chamber}

The instrument used in this research is DSF580I multi-functional hypoxic chamber (Fig. 2) with 4 modes of hypobaric hypoxia, hypobaric normoxia, normobaric hypoxia and low $\mathrm{O}_{2}$ and carbon dioxide $\left(\mathrm{CO}_{2}\right)$. One of four modes or compound patterns can be selected according to the experimental requirement. The multi-functional hypoxic chamber mainly consists of the cabin

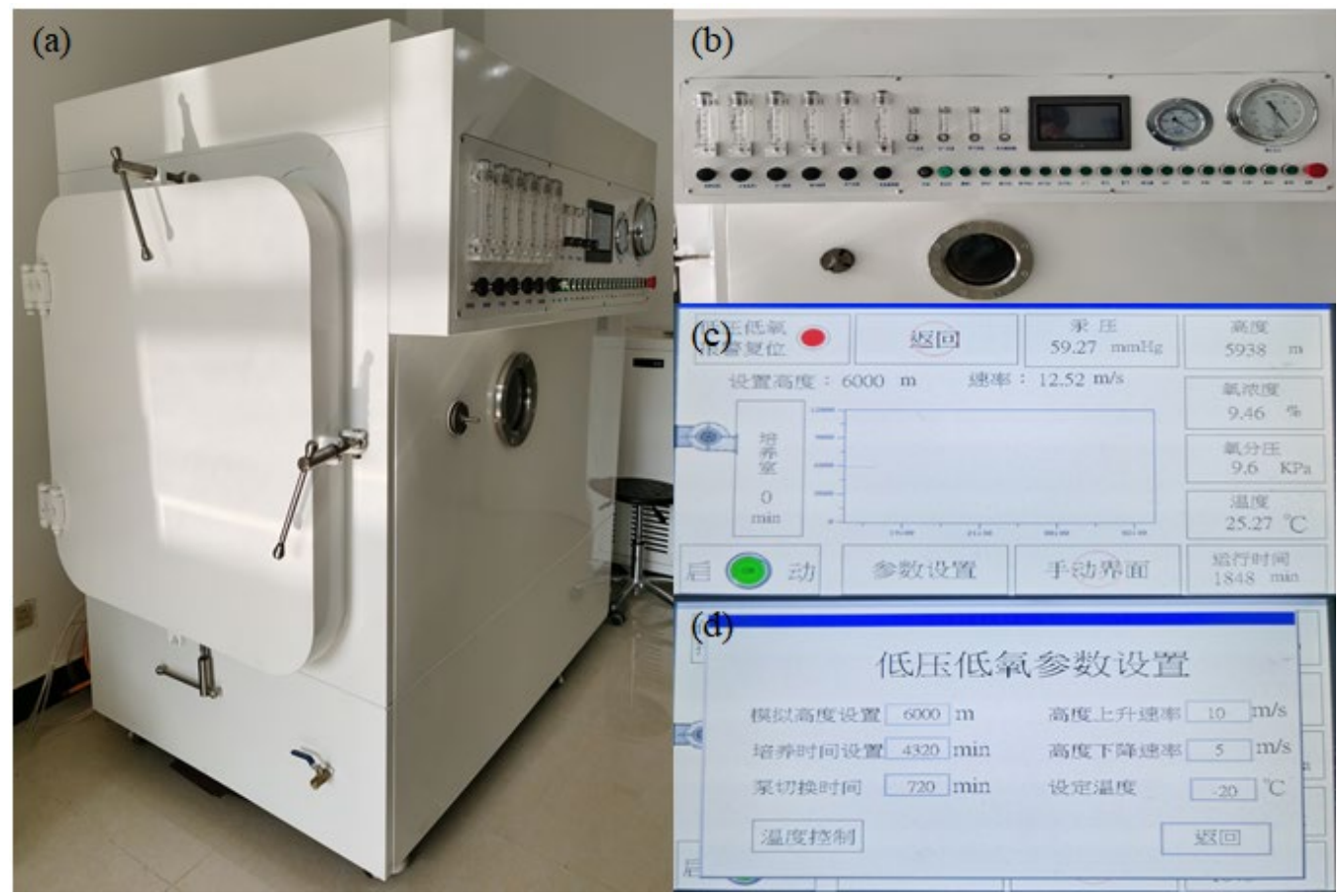

Fig. 2. Multi-functional hypoxic chamber. (a) The main body of the multi-functional hypoxic chamber; (b) Control part; (c) Parameter settings of $\mathrm{HBH}$; (d) Running interface. 
and the control part whose interior is large enough to hold 4-5 rat cages (Fig. 2(a)). Cameras are mounted on the door and the inside of the cabin, which can be used to monitor the animals inside through the external display screen. There is a touch screen and several control buttons including regulating $\mathrm{O}_{2}$ and nitrogen $\left(\mathrm{N}_{2}\right)$ in the control part (Fig. 2(b)). The working mode and the system parameters are set by the touch screen.

\subsection{Experimental Design and the Simulation Conditions of HA Atmospheric Environment}

An overview of the study is provided in Fig. 3. Thirty-two SD rats were randomly divided into four groups: the control group $(n=8)$ and the exposed groups $(n=24)$. The exposed groups were divided into three groups according to different exposure levels $(24,48$, and 72 hours) ( $n=8$, respectively). The multi-functional hypoxic chamber (Fig. 2) described above was used to simulate HA atmospheric conditions to obtain HAPE model, the altitude was set at $6000 \mathrm{~m}$ according to the previous research. Other parameter settings include oxygen concentration of $9.46 \%$, partial oxygen pressure of $9.6 \mathrm{KPa}$, culture time (1440 min, $2880 \mathrm{~min}$ and $4320 \mathrm{~min}$ ), pump switching time $(720 \mathrm{~min})$, rate of elevation $\left(10 \mathrm{~m} \mathrm{~s}^{-1}\right)$, rate of descent $\left(5 \mathrm{~m} \mathrm{~s}^{-1}\right)$ and cabin temperature $\left(-20^{\circ} \mathrm{C}\right)$ (Figs. $\left.2(\mathrm{c}-\mathrm{d})\right)$.

\subsection{Lung Wet/Dry (W/D) Weight Ratio}

The magnitude of pulmonary edema was determined by weighing and computing W/D ratio of the pulmonary tissues. The left lobe of the lung was excised, washed several times with $0.9 \%$ $\mathrm{NaCl}$, and the excess moisture on the surface of the lung tissue was blotted gently using a clean filter paper. The lung tissue was weighed to obtain wet weight and then placed together with the foil in an electric thermostatic oven at $60^{\circ} \mathrm{C}$ for $48 \mathrm{~h}$, finally the weight was recorded as the dry weight. The W/D ratio of the lung tissue was calculated to assess the degree of pulmonary edema.

\subsection{Hematoxylin and Eosin (HE) Staining}

Lung tissues were fixed in $4 \%$ paraformaldehyde for $48 \mathrm{~h}$ and then sectioned and stained. Eight different areas were randomly selected from the control group and the exposed groups. Lung tissue structure, lung septum, and red blood cell exudation were observed under light microscopy. Inflammatory cell infiltration and pulmonary edema images were collected by optical microscope. The severity of lung injury was based on the following scoring criteria: no damage = 0 point; $25 \%$ injury area $=1$ point; $50 \%$ injury area = 2 points; $75 \%$ injury area $=3$ points; total lung injury = 4 points (Smith et al., 1997). The extent of lung tissue damage was observed and scored using the double-blind method by two pathologists.

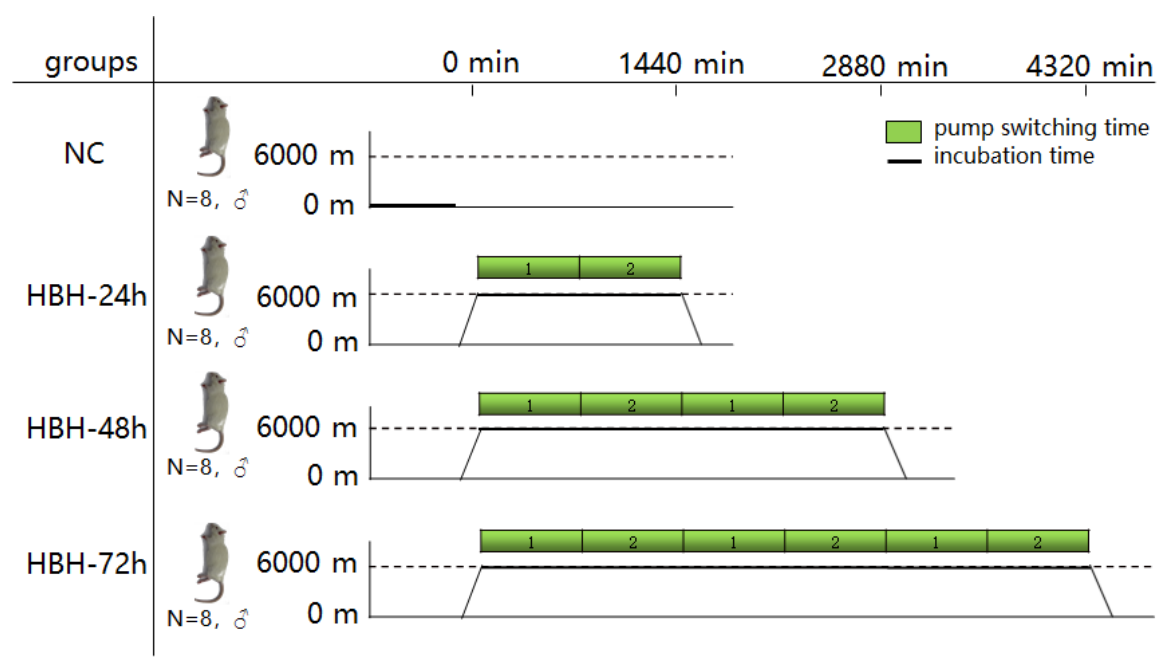

Fig. 3. Overview of experimental approach. Rats were assigned to control (NC), hypobaric hypoxia (HBH)-24h, HBH-48h and HBH-72h exposed groups. The altitude was set at $6000 \mathrm{~m}$, and the pump operating time was 720 min. 
Table 1. PCR and pyrosequencing primer sequences.

\begin{tabular}{lll}
\hline Gene name & Primer & Sequence \\
\hline MT-Cox1 & Forward primer (5' to $\left.3^{\prime}\right)$ & AGTTGGAGTTGGAATAGGATGAATA \\
& Reverse biotin primer $\left(5^{\prime}\right.$ to $\left.3^{\prime}\right)$ & TAACTCCTAAAATAAAAAACACCCC \\
& Sequencing primer $\left(5^{\prime}\right.$ to $\left.3^{\prime}\right)$ & ATATTTTTTTTAGT \\
MT-Cox2 & Forward primer $\left(5^{\prime}\right.$ to $\left.3^{\prime}\right)$ & TAATGATTAAAATTAGGTGAATTT \\
& Reverse biotin primer $\left(5^{\prime}\right.$ to $\left.3^{\prime}\right)$ & TAACCCTAATAAAAAAATACTCATAAATA \\
MT-Cox3 & Sequencing primer $\left(5^{\prime}\right.$ to $\left.3^{\prime}\right)$ & ATAGAATTTTAATT \\
& Forward primer $\left(5^{\prime}\right.$ to $\left.3^{\prime}\right)$ & GTTATTATATTTTTATTGTATAAAAAGGTT \\
& Reverse biotin primer $\left(5^{\prime}\right.$ to $\left.3^{\prime}\right)$ & AAATAATAAAATACTCAAAAAATCC \\
& Sequencing primer $\left(5^{\prime}\right.$ to $\left.3^{\prime}\right)$ & GTATAAAAAGGTTTT \\
\hline
\end{tabular}

\subsection{Platelet mtDNA Methylation}

The whole blood was centrifuged to obtain plasma, the samples were frozen and stored at $-80^{\circ} \mathrm{C}$ until analysis. Platelet mtDNA was extracted from plasma samples, and methylation levels of platelet mtDNA candidate sites for platelet mtDNA associated with lung function were detected by pyrosequencing. PyroMark Q96 MD pyrosequencing system (QIAGEN, Germantown, MD) was used for pyrosequencing. The methylation levels of MT-Cox1, MT-Cox2 and MT-Cox3 genes encoding cytochrome $C$ enzyme were determined by bisulfite pyrosequencing. The Meth Primer program was used to design primer sequences based on the GeneBank: J01415.2 (L-strand) mitochondrial genome sequence and the specific information was supplied in Table 1. In detail, one CpG position for MT-Cox1 region; two CpG positions for MT-Cox3 region and three CpG positions for MT-Cox2 region were quantified.

\subsection{Measurement of Plasma Inflammatory Cytokines}

The Bio-Plex Pro ${ }^{\mathrm{TM}}$ Rat Cytokine Th1/Th2 Assay was used to detect plasma inflammatory mediators in all groups (Bio-Rad, Hercules, CA). Luminex Bio-Plex Pro Rat Cytokine Th1/Th2 Panel 12-Plex based on the coupled magnetic beads allowed the simultaneous quantification of 12 cytokines from previously stored plasma, including IL-1 $\alpha$, IL-1 3 , IL-2, IL-4, IL-5, IL-6, IL-10, IL-12 (p70), IL-13, TNF- $\alpha$, GM-CSF and IFN- $\gamma$. Twelve groups of fluorescently staining beads were coupled with target-specific reactants to trigger biochemical reactions with target biomolecules, which were detected by Bio-Plex MAGPIX System (Bio-Rad). A high-speed digital signal processor was used to process the fluorescent output, and the Bio-Plex Manager ${ }^{\mathrm{TM}}$ software was used to calculate cytokine concentrations automatically based on a standard curve.

\subsection{Statistical Analysis}

Analyses were performed using the GraphPad Prism 8.0.1 software program. Paired t-test were used to calculate the significant differences in the methylation levels of a given gene in platelets between the control and exposed groups. Significance of the difference in methylation exposure at each site was calculated by Brown-Forsythe and Welch one-way analysis of variance (ANOVA). One-way ANOVA was used for comparisons between groups of lung injury score and the W/D ratio. The significance analysis and degree of relevance were performed to determine by linear regressions. $\mathrm{P}$ value $<0.05$ represented statistically significant.

\section{RESULTS AND DISCUSSION}

\subsection{AQI and $\mathrm{PM}_{2.5}$ Concentrations in Tibet}

The monthly AQI and $\mathrm{PM}_{2.5}$ concentrations in Tibet included seven cities during 2020 were processed and shown in Fig. 4. The data were derived from the $\mathrm{PM}_{2.5}$ Historical Data Network (https://www.aqistudy.cn/historydata/). In 2020, the monitored AQI in Tibet varied from 24 to 98 and averaged 48 , which was below 50 , indicating that the air quality in Tibet was quite excellent (Bhaskar et al., 2017). The annual $\mathrm{PM}_{2.5}$ concentrations ranged between 3.0 and $31 \mu \mathrm{g} \mathrm{m}^{-3}$ and with an average of $10 \mu \mathrm{g} \mathrm{m}^{-3}$, which was lower than the National Ambient Air Quality Primary 
Standard of $\mathrm{PM}_{2.5}\left(15 \mu \mathrm{g} \mathrm{m}^{-3}\right)(\mathrm{GB} 3095-2012)$ (Cao et al., 2019).

In 2020, the April, May, and June were with the highest AQI and were 52, 63, and 54, respectively; while the highest $\mathrm{PM}_{2.5}$ concentrations were occurred in winter, including January $\left(12 \mu \mathrm{g} \mathrm{m}^{-3}\right)$, November $\left(14 \mu \mathrm{g} \mathrm{m}^{-3}\right)$ and December $\left(16 \mu \mathrm{g} \mathrm{m}^{-3}\right)$. The above results indicated that the $\mathrm{O}_{3}$ and $\mathrm{NO}_{\mathrm{x}}$ other than $\mathrm{PM}_{2.5}$ were the major indicatory pollutants for AQI during April, May and June, which were owing to solar radiation and temperature (Cifuentes et al., 2021) and the emission from vehicles (Peng et al., 2021). Among the sub-cities in Tibet, as to the AQI, the Ali area had the highest average, while the Nyingchi had the lowest, and they were 58 and 40, respectively. However, the Nagqu had the highest average $\mathrm{PM}_{2.5}$ concentration and the Ali area had the lowest one; they were 18 and $6.0 \mu \mathrm{g} \mathrm{m}^{-3}$, respectively.

\subsection{The Oxygen Concentration and Partial Oxygen Pressure in Different Altitudes and the Composition of Atmosphere}

It is well known that the atmosphere is consist of many kinds of components, such as $\mathrm{N}_{2}, \mathrm{O}_{2}$, inert gases, $\mathrm{CO}_{2}$ and other gases. The volume fraction of oxygen in atmosphere is $21 \%$, which cannot change with the increased altitude. However, the partial pressure of atmospheric oxygen falls progressively as barometric pressure decreases with increasing altitude (Grocott et al., 2009). As displayed in Fig. 5(a), the oxygen concentration and partial pressure of oxygen in Tibet (4000$5000 \mathrm{~m}$ ) decreased significantly compared with the plain areas (less $50 \mathrm{~m}$ above the mean sea level).

It can be demonstrated that the overall environmental air quality in HA areas was relatively better compared with plain areas when coupled with the graphic information (Figs. 4 and 5). On the other hand, the bar chart showed a remarkable decline in the oxygen concentration and partial oxygen pressure from plain areas to HA areas. Meanwhile, the partial pressure of inspired oxygen $\left(\mathrm{PiO}_{2}\right)$ would diminish with the decreased availability of atmospheric oxygen for aerobic respiration (Grocott et al., 2009), which could cause the tissue hypoxia and subsequently trigger a considerable number of regulatory mechanisms. Therefore, it can be further indicated that the relatively larger contribution of $\mathrm{HBH}$ in the atmospheric environment to the health of people entering the HA.

\subsection{The Methylation Levels of Platelet mtDNA Before and After Exposure}

The methylation levels of platelet mtDNA of three genes were measured in the plasma platelets of rats exposed to $\mathrm{HBH}$ for $24 \mathrm{~h}, 48 \mathrm{~h}$ and $72 \mathrm{~h}$ in the multi-functional hypoxic chamber: MT-Cox 1 ;

(a)

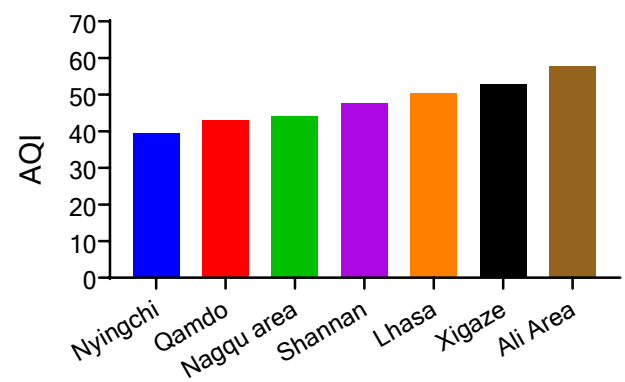

m (c)

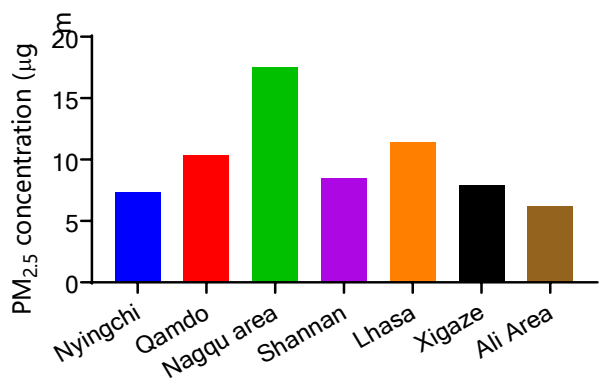

(b)

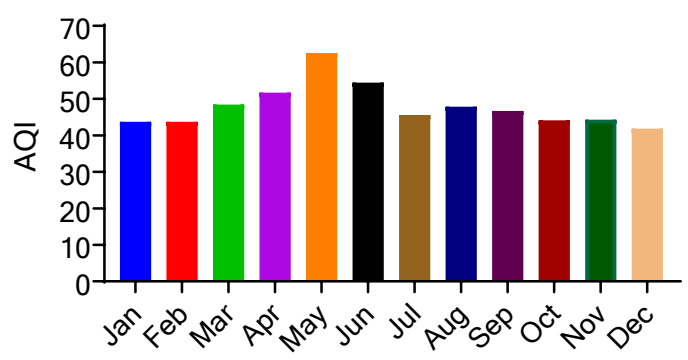

n (d)

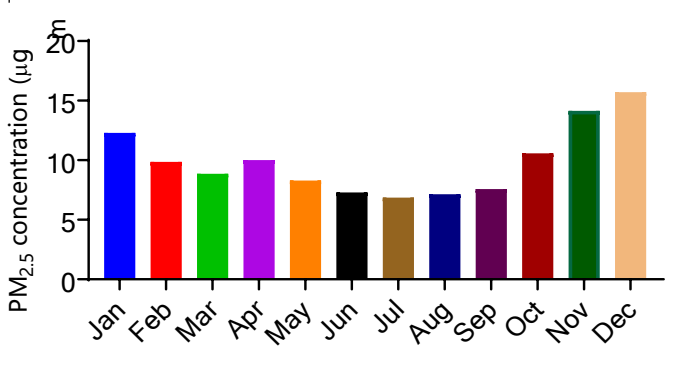

Fig. 4. The $A Q I$ and $P M_{2.5}$ concentration in Tibet in 2020. 

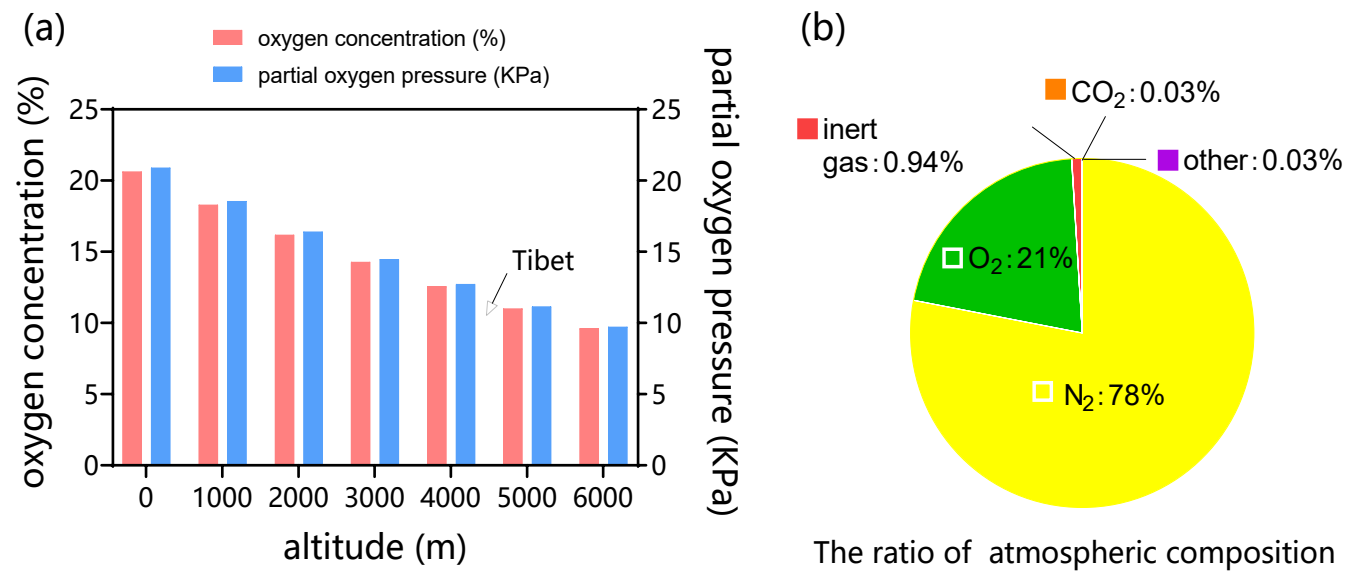

The ratio of atmospheric composition

Fig. 5. The oxygen concentration and partial oxygen pressure in (a) different altitudes and (b) the composition of atmosphere.

MT-Cox2 and MT-Cox3. The basal DNA methylation level of each gene included different CpG sites varied between the three gene regions studied here. Following HBH exposure for $24 \mathrm{~h}, M T-C o x 1$, MT-Cox2 and MT-Cox3 methylation levels were all significantly decreased. Following HBH exposure for $48 \mathrm{~h}, M T$-Cox1, MT-Cox2 except for MT-Cox2_Pos2 and MT-Cox3 methylation levels were significantly decreased. Following HBH exposure for $72 \mathrm{~h}$, MT-Cox1, MT-Cox2_Pos1 and MT-Cox3 methylation levels were significantly decreased. The levels of MT-Cox2 methylation in other CpG sites decreased with HBH exposure although did not achieve statistical significance (Fig. 6).

\section{4 mtDNA Methylation Changes in MT-Cox Genes between Before and After $\mathrm{HBH}$ Exposure}

The levels of $\mathrm{HBH}$ exposure were negatively correlated with the absolute changes in methylation of MT-Cox1, MT-Cox2 and MT-Cox3 genomic regions of platelet mtDNA. We did not observe an ascending effect upon absolute changes in mtDNA methylation following $\mathrm{HBH}$ exposure between three exposed groups. On the contrary, there was marginally significant reduction in the change of MT-Cox2_Pos3 methylation in $\mathrm{HBH}-24 \mathrm{~h}$ compared with the $\mathrm{HBH}-48 \mathrm{~h}$ exposed group $(\mathrm{p}<0.05)$. The results indicated that the $\mathrm{HBH}$ exposure time had a negative relation with the MT-Cox methylation levels (Fig. 7).

As extensive studies have indicated that changes in epigenetic levels between environmental factors and altered gene expression may be indirect factors leading to the emergence of some disease phenotypes. Environmental exposures to physical, chemical and nutritional factors can cause epigenetic changes potentially by altering gene expression and modifying individual illness susceptibility in multiple pathways (Jirtle and Skinner, 2007). For instance, it has been found that exposure to PM could increase the risk of lung cancer in individuals through touching off systemic inflammation and DNA hypomethylation of leukocyte (Guo et al., 2014; Chao et al., 2018). Associated with particle-containing welding fumes exposure, a recent study of 101 welders from southern Sweden showed that the D-loop and MT-TF genes became hypomethylated, indicating that oxidative stress was related to the exposure (Xu et al., 2017). Yang et al. (2016) suggested that the MT-RNR1 and MT-TF genes in mtDNA methylation were decreased whereas the LINE-1 gene in nDNA remained unaltered in chrome plating exposed workers. And the findings from Sanyal, et al. (2018) concluded that mtDNA methylation could be impacted by chronic arsenic toxicity, meanwhile, the expression of certain mitochondrial gene enhanced, and mitochondrial biogenesis increased in arsenic-exposed population compared with individuals who were not exposed to arsenic. In our study, we identified hypomethylation of $M T$-Cox after $\mathrm{HBH}$ exposure, indicating a mechanism by which $\mathrm{HBH}$ exposure could affect mitochondrial functions such as mitochondrial gene expression and oxidative stress. Moreover, the levels of $\mathrm{HBH}$ exposure were negatively correlated with the absolute changes in methylation of MT-Cox1, MT-Cox2 and MT-Cox3 genomic regions of platelet mtDNA. However, the absolute changes did not reach statistical significance between three $\mathrm{HBH}$ exposed groups except for the absolute change of $\mathrm{HBH}-24 \mathrm{~h}$ exposed group 
(a)

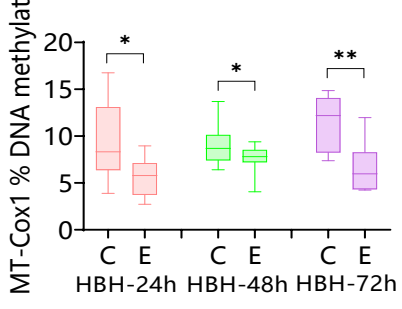

$\frac{.0}{\frac{0}{\pi}}(d)$

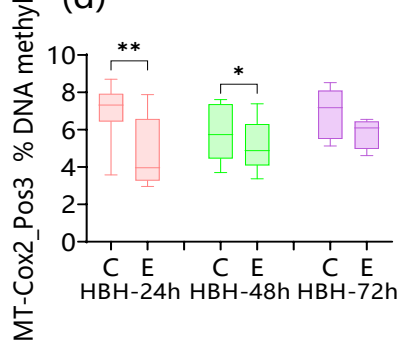

$(\mathrm{g})$

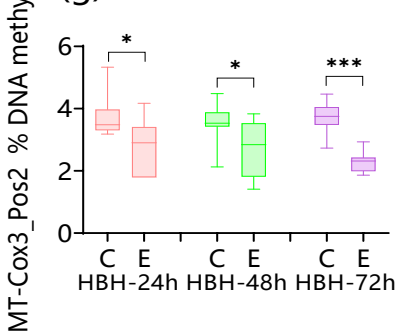

을 (b)

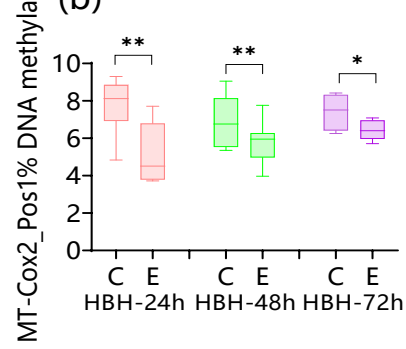

을 (e)

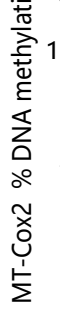

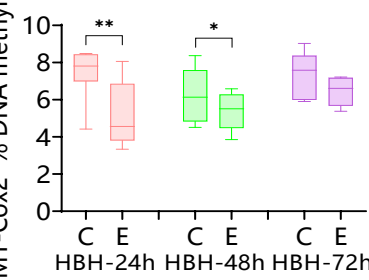

HBH: hypobaric hypoxia

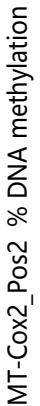

(c)

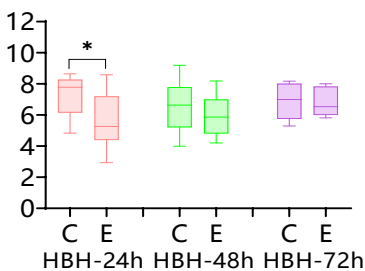

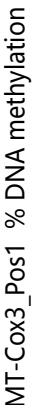

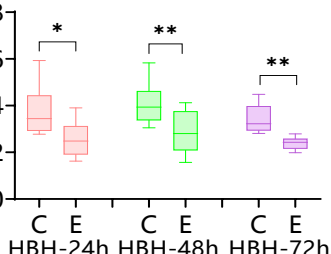

Fig. 6. Methylation changes after $\mathrm{HBH}$ exposure for 24,48 , and 72 hours in rats platelet mtDNA. Platelet mtDNA methylation changes in (a) MT-Cox1; (b) MT-Cox2_Pos1; (c) MT-Cox2_Pos2; (d) MT-Cox2_Pos3; (e) MT-Cox2; (f) MT-Cox3_Pos1; (g) MT-Cox3_Pos2; (h) MT-Cox3 in the plasma platelet mtDNA of control and exposed rats. Box: median. Bars: $\min$ and max values. C: control and E: exposed group. ${ }^{*} p<0.05,{ }^{* *} p<0.01,{ }^{* * *} p<0.001$ indicated the significance of the estimated effect value. $\mathrm{HBH}$ : hypobaric hypoxia exposed group.

compared with HBH-48h in MT-Cox2_Pos3. We speculate that the alteration in MT-Cox3 methylation in $\mathrm{HBH}-24 \mathrm{~h}$ and $\mathrm{HBH}-48 \mathrm{~h}$ exposed groups may be implicated in different $\mathrm{HBH}$ exposure levels, although further studies are required to analyze this correlation in detail. $\mathrm{HBH}$-induced oxidative stress affects nitric oxide (NO), an endothelium derived mediator, leading to the accumulation of harmful mediators such as peroxy-nitrite, which limits vasodilating potential mediated by NO in the bodies, restraining the activation/aggregation of platelet consequently (Faiss et al., 2013; Gresele et al., 2019). Concurrently, mtDNA is one foremost target of oxidative stress generated by environmental exposure (Xu et al., 2017), therefore, future studies are warranted to determine whether MT-Cox hypomethylation after HBH exposure is related to mitochondrial oxidative stress and gene expression.

\subsection{Analysis of W/D of Lung Tissue}

All groups were randomly selected, and W/D ratio was significantly higher in exposed groups with increased $\mathrm{HBH}$ exposure level. Compared with the control group, W/D ratio and lung injury score were elevated significantly in HAPE rats after HBH exposure $(p<0.05)$. However, the difference between HBH-24h exposed group and control group was not observed (Fig. 8(a)). 

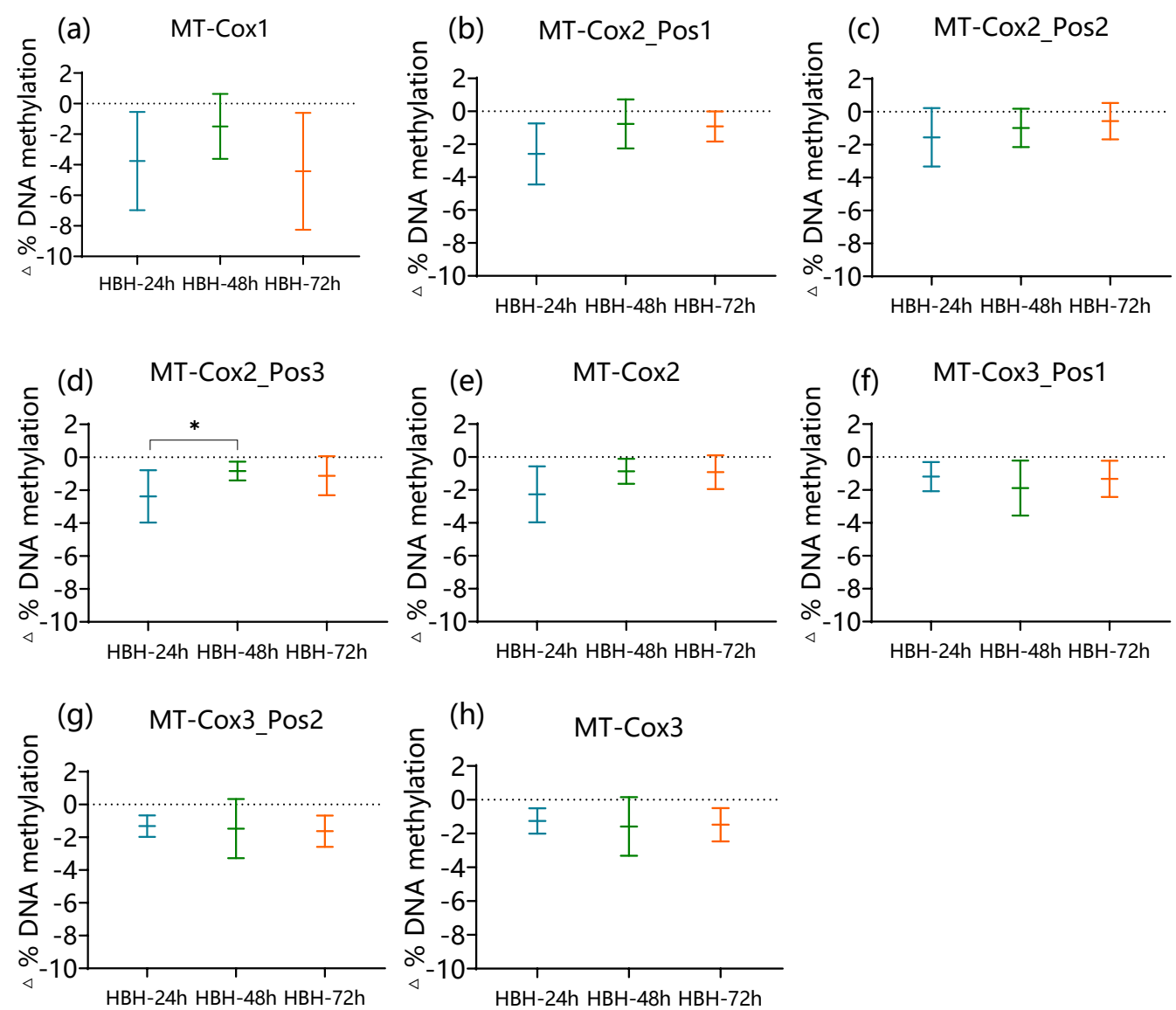

Fig. 7. Association between three $\mathrm{HBH}$ exposure levels and the absolute changes $(\Delta)$ in levels of platelet mtDNA methylation in all HAPE rats in the multivariable linear regression models. (a) $M T$ Cox1; (b) MT-Cox2_Pos1; (c) MT-Cox2_Pos2; (d) MT-Cox2_Pos3; (e) MT-Cox2; (f) MT-Cox3_Pos1; (g) MT-Cox3_Pos2; (h) MT-Cox3. Note: the methylation variables were defined by percentage changes (\%) before to after the $\mathrm{HBH}$ exposure, and the $95 \%$ confidence interval was represented as vertical lines; ${ }^{*} \mathrm{p}<0.05$ suggested statistically significance of the estimated effect value. $\mathrm{HBH}$ : hypobaric hypoxic exposed group.

\subsection{Pathological Changes in the Lung Tissue}

$\mathrm{HE}$ staining of the rats lung tissue showed that the alveolar structure was integrated in the control group, the pulmonary septum was basically not thickened, erythrocyte distribution was observed and obvious edema was not observed in lung interstitium or the alveolar cavity. We observed significant pathological variations in the lung tissues of $\mathrm{HBH}$-challenged rats, including pulmonary interstitial edema, pulmonary capillary congestion, considerable inflammatory cell infiltration into the alveolar space and lung interstitium, and thickened alveolar wall (Figs. 8(c-f)). The lung tissue score was significantly elevated in the exposed groups compared with the control group ( $<<0.05$ ) (Fig. 8(b)).

\subsection{Correlation of mtDNA Methylation with W/D of Lung Tissue}

The changes of W/D ratio with $\mathrm{HBH}$ exposure were remarkably related to $M T-\operatorname{Cox} 1(\mathrm{r}=-0.1644$, $p=0.0493), M T-C o x 2 \_P o s 2(r=-0.1935, p=0.0315)$ and MT-Cox2_Pos3 $(r=-0.1695, p=0.0456)$ methylation. The remaining methylation sites of $M T$-Cox did not show significant correlations with W/D ratio (Fig. 9).

Change in mtDNA levels is increasingly applied to a biomarker of mitochondrial dysfunction (Sun et al., 2021). As a vital and promising research, the role of mitochondrial dysfunction and its 
(a)
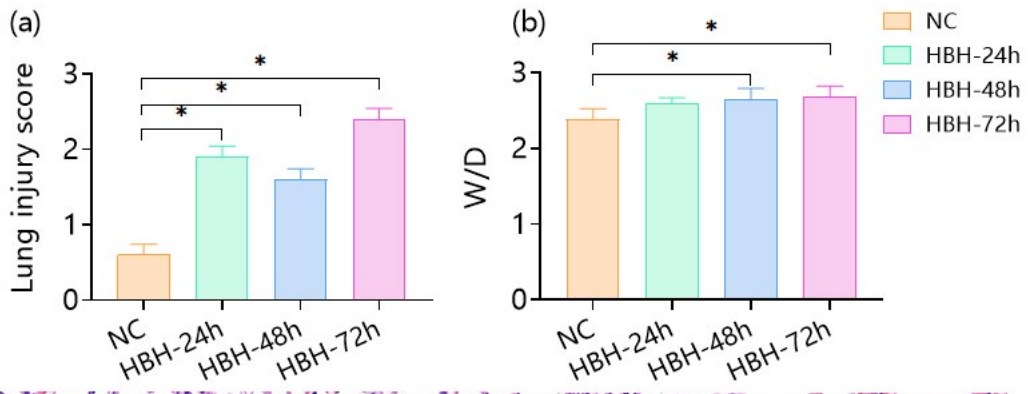

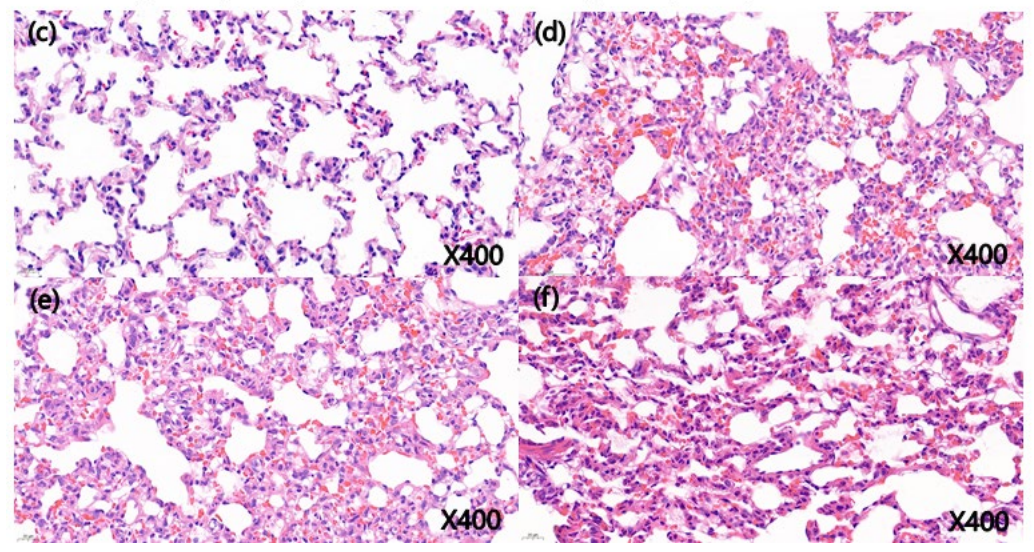

Fig. 8. W/D ratio and HE pathological staining of lung tissue in rats $(\times 200)$. The evaluation of the lung injury score was due to the pathology detected by using $\mathrm{HE}$ staining. (a) W/D; (b) Lung injury score; (c) Control group; (d) $\mathrm{HBH}-24 \mathrm{~h}$ exposed group; (e) $\mathrm{HBH}-48 \mathrm{~h}$ exposed group; (f) $\mathrm{HBH}-72 \mathrm{~h}$ exposed group. NC: control group; $\mathrm{HBH}$ : hypobaric hypoxic exposed group.
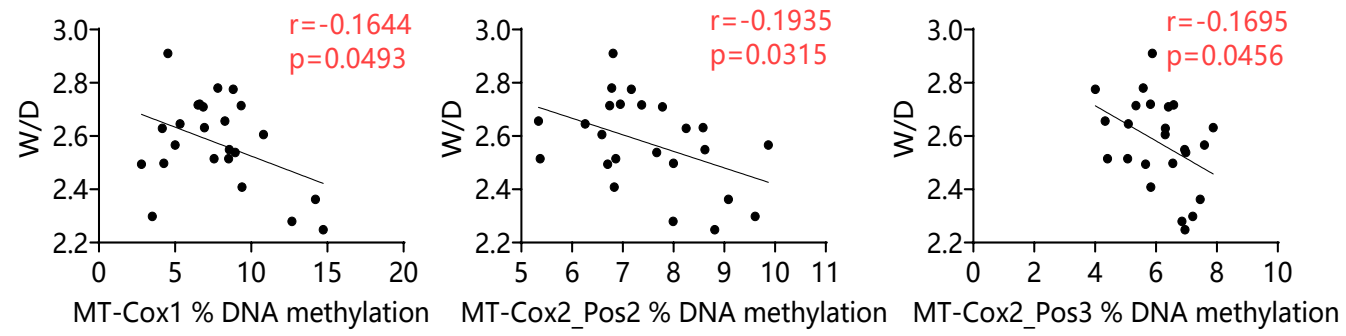

Fig. 9. Correlation of changes in W/D ratio of lung tissue and MT-Cox methylation. The correlation between the W/D ratio and DNA methylation by $\mathrm{HBH}$ exposure is illustrated, with significant differences indicated. The values of $r$ and $p(p<0.05)$ are shown in the figures above.

potential mechanistic in the evolution of lung diseases is highly acknowledged (Ten and Ratner, 2020). Platelets have interrelated activities with lung, which is a complex multicellular organ responsible for many physiologic processes, such as gas exchange and immune surveillance (Bozza et al., 2009). It has been proven that platelets were a crucial element of acute lung injury (ALI), exerting synergistic action with fibrinogen to mediate endothelial damage via various pathways of signal transduction (Dixon et al., 2012). The platelet-derived growth factor beta beta (PDGF- $\beta \beta$ ), a biomarker, is known to be associated with the smooth muscle proliferation and processes of exaggerated vasoconstriction that are hallmark characteristics of HAPE (Pandey et al., 2016). Additionally, the link between elevation of W/D ratio and increased endothelium swelling or epithelium disruption indicated that the defeat of alveolar capillary barrier stress played a pivotal role in the development of HAPE, suggesting that the W/D ratio of lung was an indicator of overall pulmonary edema severity (Bai et al., 2010; Wu et al., 2019). There was a strong relation between decreased MT-Cox1, MT-Cox2_Pos2, MT-Cox2_Pos3 methylation in the plasma platelets and increased W/D ratio after $\mathrm{HBH}$ exposure from our study. Although, the correlations between MT-Cox2_Pos1 and MT-Cox3 (including 2 CpG sites) methylation with W/D 
ratio were decreased with $\mathrm{HBH}$ exposure, none of them was statistically significant. We conject that the changes in MT-Cox1, MT-Cox2_Pos2, MT-Cox2_Pos3 methylation might be implicated with increase of W/D ratio. Given that platelet mtDNA methylation has been shown to contribute to mitochondrial dysfunction, platelet mtDNA methylation is a plausible epigenetic risk factor to investigate in many diseases. A previous study has proven that the development of CVD could be promoted by platelet mtDNA methylation through regulating platelet activity (Baccarelli and Byun, 2015). Concurrently, recent evidence supported that the variation of platelet mtDNA methylation might be involved in the complex multifactorial disease pathogenesis, such as the association between trimethylamine-N-oxide (TMAO), atherosclerosis and I-carnitine, which could be more complicated than already assumed (Bordoni et al., 2020). Together above, we suggest that platelet mtDNA methylation might be involved in the process of HAPE.

\subsection{Correlation of Platelet mtDNA Methylation with Inflammatory Mediators}

A premade platform was used to detect 12 inflammatory cytokines levels of rats' plasma and analyze their correlation with mtDNA methylation of MT-Cox genes (Bio-Plex Pro Rat Cytokine Th1/Th2 Panel 12-Plex (Bio-Rad, Hercules, CA). As shown in Fig. 10, seven proinflammatory cytokines in plasma following $\mathrm{HBH}$ exposure were significantly associated with MT-Cox2 methylation (including $3 \mathrm{GpG}$ sites) ( $r=0.09-0.30, p<0.05)$. In contrast, MT-Cox3_Pos3 methylation was inversely related to proinflammatory cytokines $(r=-0.1506, p=0.0341))$. MT-Cox 1 and the remaining methylation sites of MT-Cox3 showed no significant correlation with cytokine levels at the same p value (Fig. 10).

Studies have shown that platelet function is closely related to inflammation. Sreeramkumar et al. (2014) suggested that dynamic recombination of neutrophil domains and receptors provided a rapid and effective regulatory mechanism in the early stages of inflammation by simultaneously interacting with vascular walls and activated platelets in circulation. A growing body of data revealed that platelets were active cell populations in atherosclerosis and a key cross-link between inflammation and thrombosis (Yin et al., 2019). Additionally, platelets are capable of releasing mitochondria, and mtDNA is a recognized damage-associated molecular pattern detected in considerable inflammatory situations and in the concentrates of platelet, damage to which can cause inflammation and bioenergetic deficit (Mills et al., 2017). Hyperreactive platelets with larger mitochondrial mass have the potential of exacerbating inflammatory responses by releasing higher amounts of mitochondrial DNA and other inflammatory mitochondrial components (DavizonCastillo et al., 2019). To sum up, there is an important association between inflammatory response and abnormal mitochondrial function of platelets.

Once facing pressure, mitochondria produce ROS and release mitochondrial components, such as mtDNA, into cytoplasm or extracellular matrix in order to control inflammation (Suarez-Rivero et al., 2021). This phenomenon has been described before (Ma, 2015). that mtDNA was damaged as early as at the initiation of proinflammatory cytokine release and TNF- $\alpha$ induced DNA damage by increasing mitochondrial mtROS. Plenty of evidences suggested that mtDNA damage induced by inflammation might be involved in a wide variety of lung diseases. For example, Hu et al. (2015) suggested that inflammation could be activated and the release of TNF- $\alpha$, IL- 6 , and IL-10 could be accelerated by mtDNA during the injury of liver ischemia-reperfusion. The complex of CrampmtDNA has been found to deteriorate the proinflammatory effect of neutrophils on septic mice and disadvantageous tissue damage could be further induced (Zuo et al., 2019). And Jing and Hu et al. (2020) showed that CS up-regulated PINK1 expression, mitochondrial autophagy occurred due to the release of mtDNA, the TLR9/MyD88 pathway was activated, finally inducing inflammation and cell injury in ALI. Furthermore, Zhao et al. (2021) have emphasized that mtROS maintained mitochondrial dysfunction and inflammation that contribute to ischemic acute kidney injury through obstructing mtDNA mediated by TFAM. It has also been reported that increased cell-free mtDNA played a crucial part in the inflammatory and immune reactions during non-hemolytic transfusion reaction, severe trauma, virologically suppressed HIV-infected individuals and ischemia-reperfusion injury, which was a sign of continued inflammation and better neurocognitive function (Perez-Santiago et al., 2017; Iske et al., 2020). Observed in our present study, there were significant positive associations between seven cytokines levels (IL-1 $\alpha$, IL4, IL6, IL10, IL12, INF- $\gamma$ and TNF- $\alpha$ ) and alterations in MT-Cox 2 methylation included $3 \mathrm{CpG}$ sites following $\mathrm{HBH}$ exposure. While the methylation of MT-Cox3_Pos3 was inversely correlated with IL13 after HBH exposure. 


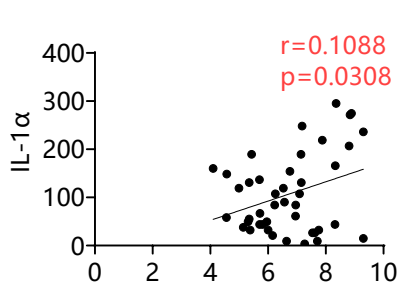

MT-Cox2_Pos1 \% DNA methylation

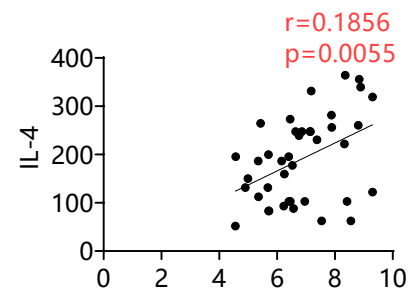

MT-Cox2_Pos1 \% DNA methylation

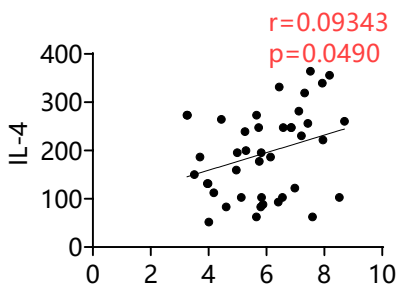

MT-Cox2_Pos3 \% DNA methylation

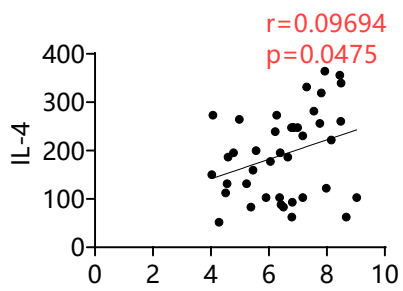

MT-Cox2 \% DNA methylation

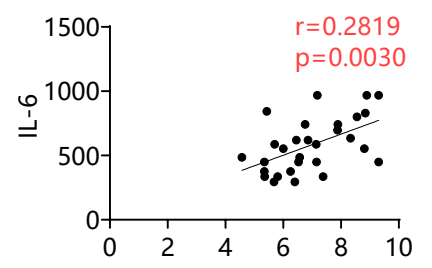

MT-Cox2_Pos1 \% DNA methylation

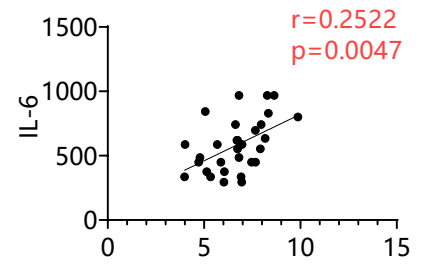

MT-Cox2_Pos2 \% DNA methylation

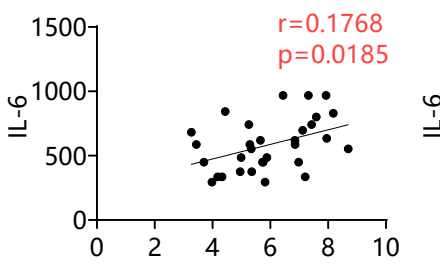

MT-Cox2_Pos3 \% DNA methylation

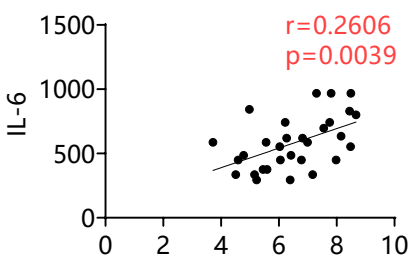

MT-Cox2 \% DNA methylation

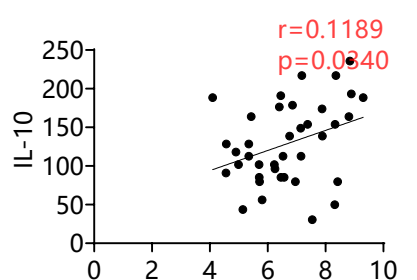

MT-Cox2_Pos1 \% DNA methylation

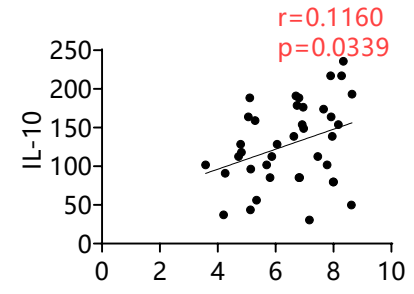

MT-Cox2_Pos2 \% DNA methylation

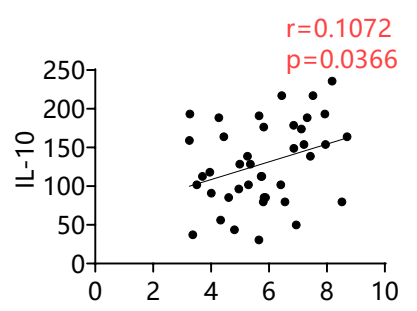

MT-Cox2_Pos3 \% DNA methylation

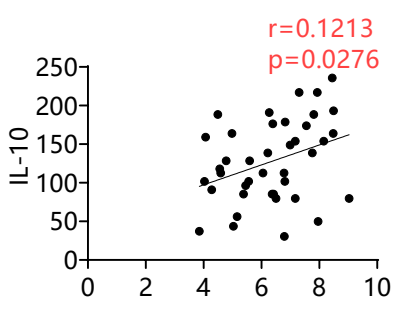

MT-Cox2 \% DNA methylation

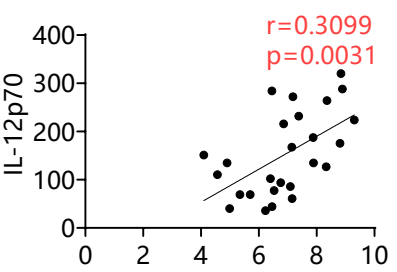

MT-Cox2_Pos1 \% DNA methylation

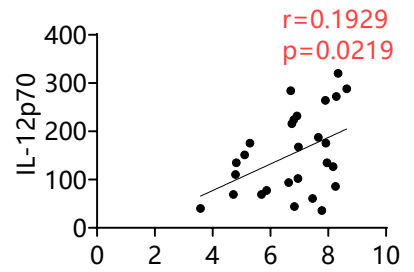

MT-Cox2_Pos2 \% DNA methylation

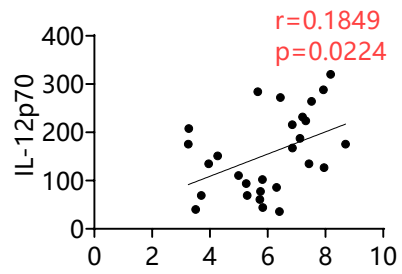

MT-Cox2_Pos3 \% DNA methylation

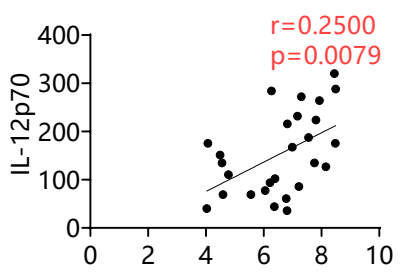

MT-Cox2 \% DNA methylation

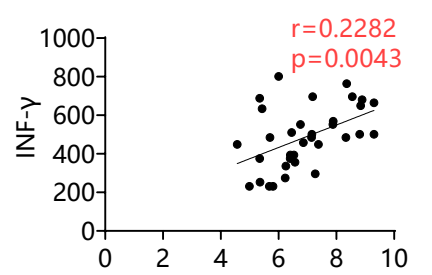

MT-Cox2_Pos1\% DNA methylation

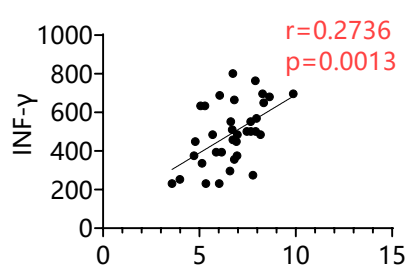

MT-Cox2_Pos2 \% DNA methylation
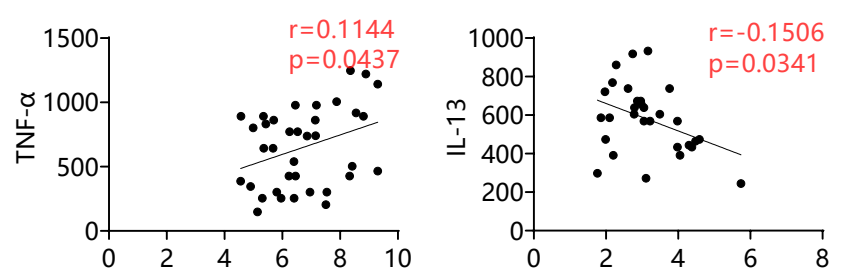

MT-Cox2_Pos1 \% DNA methylation MT-Cox3_Pos1 \% DNA methylation

Fig. 10. Correlation of changes in inflammatory markers and MT-Cox methylation. The correlation between inflammatory cytokines and DNA methylation by HBH exposure is illustrated, with significant differences indicated. The values of $r$ and $p$ ( $p<$ 0.05 ) are shown in the figures above.

However, MT-Cox methylation of other sites did not show significant associations with inflammatory cytokines. It is well learned that the levels of alveolar macrophages, neutrophils and lymphocytes, albumin, low density lipoprotein cholesterol, and proinflammatory cytokines and chemokines were all increased in bronchoalveolar lavage fluid (BALF) in HAPE patients (Xiang et al., 2016). As one of the most important immune cell types, macrophages are recruited to perform their physiological functions at the site of injury (Li et al., 2021). Additionally, DNA hypomethylation can be exacerbated by ROS stress and inflammation. With these continuous stimuli, the stress/damage and methylation in the lung act in a positive feedback manner (Guo et al., 2014). In this context, the results from our study supported the assumption that alterations of methylation could increase the risk of HAPE induced by inflammation. 
As a major part of cellular oxygen consumption in mitochondrial respiratory chain (MRC), mitochondrial Cox is critical for the generation of aerobic energy in the form of ATP (Timon-Gomez et al., 2018). MRC function is directly affected by Cox dysfunction and subsequently leads to increased leakage of mitochondrial electron (Liu et al., 2018). In our current study, we found that MT-Cox2, which had a significant correlation with W/D ratio compared with MT-Cox1 and MT-Cox3, had a stronger association with the inflammatory cytokines after $\mathrm{HBH}$ exposure. It can be inferred from our results that MT-Cox2 may play a crucial role in the process of inflammatory cytokines expression and MRC dysfunction in HAPE. Cox subunit 2 (Cox2) is an integral component of Cox, which is closely related to the mitochondrial electron transfer and ATP synthesis (Heidari et al., 2020). A previous experiment demonstrated that Cox 2 was significantly decreased in some patients whose Cox function was deficient (Brischigliaro and Zeviani, 2021) and in the ischemiareperfusion animal models (Mariero et al., 2019). Recent research reported that the Cox2 expression and the apoptosis proportion were increased remarkably in a model of chronic obstructive pulmonary disease (Yang et al., 2015). In addition, the production of ROS decreased due to the high expression of Cox2 in a feedback manner (Xiang et al., 2019). It was also reported that cigarette smoke extract (CSE) induced methylation and inactivation of the mitochondrial transcription factor (mtTFA) promoter, thereby reducing the expression of mtTFA, further resulting in the reduction of Cox2 expression, subsequent MRC dysfunction and the cell apoptosis of endothelial and epithelial in the lung (Zhang et al., 2013; Yang et al., 2015). Consequently, further studies are required to explore $\mathrm{HBH}$ exposure-induced changes of MT-Cox2 methylation and the potential mechanism of Cox2 in HAPE based on its important role in MRC function.

\subsection{Possible Mechanisms in HAPE after HBH Exposure}

There are many special natural environmental features on the $\mathrm{HA}$, such as $\mathrm{HBH}$, high solar radiation, arid, variable climate, low temperature, and geochemical anomaly, which cause great effects on human physiology and health (Zhang and Li, 2015). The bodies have to carry out a series of adaptive adjustments to achieve the purpose of adapting to the life on the HA when living on the plain enter the $\mathrm{HA}$ and under the conditions of $\mathrm{HBH}$. And the bodies clinically can appear some symptoms (also known as stress response) during the process of adjustment and adaptation (Sitko et al., 2019). The feature of HBH in HA environment has a great impact on the lung diseases especially HAPE. Lung W/D ratio is commonly used as indicator of pulmonary vascular permeability (Wu et al., 2019), which is an important characteristic of HAPE caused by $\mathrm{HBH}$ and pathological features of HAPE have been well known worldwide (Droma et al., 2001), both the lung W/D ratio and HE pathological staining are important indicators to evaluate the degree of HAPE therefore. The increased lung W/D ratio and the lung injuries showed in HE pathological staining from our results suggested that $\mathrm{HBH}$ environmental exposures indeed caused the occurrence of HAPE in rats. As mentioned above, inflammation is a vital pathogenic feature of HAPE and $\mathrm{HBH}$ can cause mitochondrial dysfunction. The MT-Cox hypomethylation, the relationship between lung W/D ratio and the levels of $M T$-Cox methylation and the correlation between the levels of inflammatory cytokines and MT-Cox methylation indicated that MT-Cox hypomethylation after $\mathrm{HBH}$ environmental exposures may be related to mitochondrial oxidative stress and gene expression, and the changes of MT-Cox methylation were involved in the occurrence of HAPE and could increase the risk of inflammation-induced HAPE.

\section{ADVANTAGES AND LIMITATIONS}

There are some advantages in this study. First of all, mtDNA is an innovational selection to investigate because of its significance in the physiological pathogenesis of lung diseases. In addition, we have conducted numerous epigenetic analyses (mtDNA methylation levels and their relationship with inflammation and W/D ratio respectively) that have contributed an extend study of the epigenome in response to HAPE due to exposure to $\mathrm{HBH}$. Finally, the design of our study has enabled the delineation of epigenetic changes related to HAPE.

There are also certain limitations that hamper us from the inferences which can be obtained from current observations. Firstly, we are unable to identify all genes influenced by $\mathrm{HBH}$ exposure owing to adopting a candidate gene pathway. Secondly, we cannot get rid of the possibility that 
other regions of the mitochondrial epigenome may be differentially methylated due to exposure. For the reason that further targets need to be identified and analyzed through a microarray-based approach. Last but not least, the study of the functional impact on the observed epigenetic changes has been precluded due to the absence of rat behavioral studies and the lack of RNA and protein samples to analyze gene expression.

\section{CONCLUSIONS}

This research investigated the air quality in plateau-Tibet and studied the effect of acute $\mathrm{HBH}$ exposure upon platelet mtDNA methylation in rat model of HAPE. The major results were summarized as follows:

1. In 2020, the monitored AQI in plateau-Tibet varied from 24 to 98 and averaged 48, while the $\mathrm{PM}_{2.5}$ concentration ranged between 3.0 and $31 \mu \mathrm{g} \mathrm{m}^{-3}$ and with an average of $10 \mu \mathrm{g} \mathrm{m}^{-3}$. The plateau-Tibet, had a good air quality, but with a lower atmospheric pressure and lower oxygen concentration.

2. This study explored the effect of acute $\mathrm{HBH}$ exposure upon platelet mtDNA methylation in rat model of HAPE. And the methylation levels of CpG positions in platelet mtDNA are measured in three genomic regions (MT-Cox1, MT-Cox2 and MT-Cox3). To our knowledge, this is the first time that the methylation changes of platelet mIDNA have been observed in $\mathrm{HAPE}$ in response to $\mathrm{HBH}$ exposure. We also reported an association between platelet mtDNA methylation of the MT-Cox genes with W/D ratio as well as inflammatory cytokines in rat model of HAPE.

3. The exposure of $\mathrm{HBH}$ in $\mathrm{HA}$ atmospheric environment indeed affect the platelet mtDNA methylation and HAPE. Our findings strengthen the understanding of the relationship between HAPE and mitochondrial epigenetic changes and demonstrate that exposures to $\mathrm{HBH}$ can lead to hypomethylation of three MT-Cox genes of platelet mtDNA.

4. The levels of MT-COx2 methylation were also found to have a significant effect on inflammatory imbalance in HAPE.

5. The results of this study will help inform further studies in the treatment of HAPE, including the functional consequences of the observed mitochondrial epigenetic changes and how they related to air quality in HA and physiological responses to HA. Additionally, our findings may contribute to accelerate the production of biomarkers of HAPE.

\section{ACKNOWLEDGMENTS}

We gratefully acknowledge the co-workers of our team. This research was funded in the Key Project of Applied Basic Research of the Logistics Support Department of the Chinese People's Liberation Army (BLB19J006).

\section{CONFLICTS OF INTEREST}

The authors declare no conflict of interest.

\section{REFERENCES}

Baccarelli, A.A., Byun, H.M. (2015). Platelet mitochondrial DNA methylation: A potential new marker of cardiovascular disease. Clin. Epigenet. 7, 44. https://doi.org/10.1186/s13148-0150078-0

Bai, C., She, J., Goolaerts, A., Song, Y., Shen, C., Shen, J., Hong, Q. (2010). Stress failure plays a major role in the development of high-altitude pulmonary oedema in rats. Eur. Respir. J. 35, 584-591. https://doi.org/10.1183/09031936.00001709

Bhaskar, B.V., Mehta, V.M. (2010). Atmospheric particulate pollutants and their relationship with meteorology in Ahmedabad. Aerosol Air Qual. Res. 10, 301-315. https://doi.org/10.4209/aaqr. 2009.10.0069 
Bilo, G., Caravita, S., Torlasco, C., Parati, G. (2019). Blood pressure at high altitude: Physiology and clinical implications. Kardiol. Pol. 77, 596-603. https://doi.org/10.33963/KP.14832

Bordoni, L., Sawicka, A.K., Szarmach, A., Winklewski, P.J., Olek, R.A., Gabbianelli, R. (2020). A pilot study on the effects of I-Carnitine and Trimethylamine-N-oxide on platelet mitochondrial DNA methylation and CVD biomarkers in aged women. Int. J. Mol. Sci. 21, 1047. https://doi.org/10.3 390/ijms21031047

Bozza, F.A., Shah, A.M., Weyrich, A.S., Zimmerman, G.A. (2009). Amicus or adversary: Platelets in lung biology, acute injury, and inflammation. Am. J. Respir. Cell. Mol. Biol. 40, 123-134. https://doi.org/10.1165/rcmb.2008-0241TR

Bravo Alvarez, H., Sosa Echeverria, R., Sanchez Alvarez, P., Krupa, S. (2013). Air quality standards for particulate matter (PM) at high altitude cities. Environ. Pollut. 173, 255-256. https://doi.org/ 10.1016/j.envpol.2012.09.025

Brischigliaro, M., Zeviani, M. (2021). Cytochrome c oxidase deficiency. Biochim. Biophys. Acta, Bioenerg. 1862, 148335. https://doi.org/10.1016/j.bbabio.2020.148335

Cao, J., Chow, J.C., Lee, F.S., Watson, J.G. (2013). Evolution of $\mathrm{PM}_{2.5}$ measurements and standards in the U.S. and future perspectives for China. Aerosol Air Qual. Res. 13, 1197-1211. https://doi.org/10.4209/aaqr.2012.11.0302

Chanana, N., Palmo, T., Newman, J.H., Pasha, M.A.Q. (2020). Vascular homeostasis at highaltitude: Role of genetic variants and transcription factors. Pulm. Circ. 10, 2045894020913475. https://doi.org/10.1177/2045894020913475

Chao, H.R., Hsu, J.W., Ku, H.Y., Wang, S.L., Huang, H.B., Liou, S.H., Tsou, T.C. (2018). Inflammatory response and $\mathrm{PM}_{2.5}$ exposure of urban traffic conductors. Aerosol Air Qual. Res. 18, 2633-2642. https://doi.org/10.4209/aaqr.2018.04.0132

Chen, P., Kang, S., Li, C., Li, Q., Yan, F., Guo, J., Ji, Z., Zhang, Q., Hu, Z., Tripathee, L., Sillanpää, M. (2018). Source apportionment and risk assessment of atmospheric polycyclic aromatic hydrocarbons in Lhasa, Tibet, China. Aerosol Air Qual. Res. 18, 1294-1304. https://doi.org/10. 4209/aaqr.2017.12.0603

Chen, P.F., Kang, S.C., Yang, J.H., Pu, T., Li, C.L., Guo, J.M., Tripathee, L. (2019). Spatial and temporal variations of gaseous and particulate pollutants in six sites in Tibet, China, during 2016-2017. Aerosol Air Qual. Res. 19, 516-527. https://doi.org/10.4209/aaqr.2018.10.0360

Cifuentes, F., Gálvez, A., González, C.M., Orozco-Alzate, M., Aristizábal, B.H. (2021). Hourly ozone and $\mathrm{PM}_{2.5}$ prediction using meteorological data - Alternatives for cities with limited pollutant information. Aerosol Air Qual. Res. 21, 200471. https://doi.org/10.4209/aaqr.200471

Danese, E., Montagnana, M., Gelati, M., Lippi, G. (2021). The role of epigenetics in the regulation of hemostatic balance. Semin. Thromb. Hemost. 47, 53-62. https://doi.org/10.1055/s-00401718400

Das, S., Ferlito, M., Kent, O.A., Fox-Talbot, K., Wang, R., Liu, D., Raghavachari, N., Yang, Y., Wheelan, S.J., Murphy, E., Steenbergen, C. (2012). Nuclear miRNA regulates the mitochondrial genome in the heart. Circ. Res. 110, 1596-1603. https://doi.org/10.1161/CIRCRESAHA.112.267732

Davizon-Castillo, P., McMahon, B., Aguila, S., Bark, D., Ashworth, K., Allawzi, A., Campbell, R.A., Montenont, E., Nemkov, T., D’Alessandro, A., Clendenen, N., Shih, L., Sanders, N.A., Higa, K., Cox, A., Padilla-Romo, Z., Hernandez, G., Wartchow, E., Trahan, G.D., Nozik-Grayck, E., et al. (2019). TNF- $\alpha-$ driven inflammation and mitochondrial dysfunction define the platelet hyperreactivity of aging. Blood 134, 727-740. https://doi.org/10.1182/blood.2019000200

Demopoulos, C., Antonopoulou, S., Theoharides, T.C. (2020). COVID-19, microthromboses, inflammation, and platelet activating factor. Biofactors 46, 927-933. https://doi.org/10.1002/ biof.1696

Dikalova, A.E., Pandey, A., Xiao, L., Arslanbaeva, L., Sidorova, T., Lopez, M.G., Billings, F.T.t., Verdin, E., Auwerx, J., Harrison, D.G., Dikalov, S.I. (2020). Mitochondrial deacetylase Sirt3 reduces vascular dysfunction and hypertension while Sirt3 depletion in essential hypertension is linked to vascular inflammation and oxidative stress. Circ. Res. 126, 439-452. https://doi.org/10.116 1/CIRCRESAHA.119.315767

Dixon, J.T., Gozal, E., Roberts, A.M. (2012). Platelet-mediated vascular dysfunction during acute lung injury. Arch. Physiol. Biochem. 118, 72-82. https://doi.org/10.3109/13813455.2012.665463

Droma, Y., Hanaoka, M., Hotta, J., Naramoto, A., Koizumi, T., Fujimoto, K., Honda, T., Kobayashi, T., Kubo, K. (2001). Pathological features of the lung in fatal high altitude pulmonary edema 
occurring at moderate altitude in Japan. High. Alt. Med. Biol. 2, 515-523. https://doi.org/10.10 89/152702901753397081

Eicher, J.D., Lettre, G., Johnson, A.D. (2018). The genetics of platelet count and volume in humans. Platelets 29, 125-130. https://doi.org/10.1080/09537104.2017.1317732

Eichstaedt, C.A., Benjamin, N., Grunig, E. (2020). Genetics of pulmonary hypertension and highaltitude pulmonary edema. J. Appl. Physiol. 128, 1432-1438. https://doi.org/10.1152/japplphy siol.00113.2020

Faiss, R., Pialoux, V., Sartori, C., Faes, C., Deriaz, O., Millet, G.P. (2013). Ventilation, oxidative stress, and nitric oxide in hypobaric versus normobaric hypoxia. Med. Sci. Sports Exerc. 45, 253-260. https://doi.org/10.1249/MSS.0b013e31826d5aa2

Gresele, P., Momi, S., Guglielmini, G. (2019). Nitric oxide-enhancing or - releasing agents as antithrombotic drugs. Biochem. Pharmacol. 166, 300-312. https://doi.org/10.1016/j.bcp.201 9.05.030

Grocott, M.P.W., Martin, D.S., Levett, D.Z.H., McMorrow, R., Windsor, J., Montgomery, H.E. (2009). Arterial blood gases and oxygen content in climbers on Mount Everest. N. Engl. J. Med. 360, 140-149. https://doi.org/10.1056/NEJMoa0801581

Guo, L., Byun, H.M., Zhong, J., Motta, V., Barupal, J., Zheng, Y., Dou, C., Zhang, F., McCracken, J.P., Diaz, A., Marco, S.G., Colicino, S., Schwartz, J., Wang, S., Hou, L., Baccarelli, A.A. (2014). Effects of short-term exposure to inhalable particulate matter on DNA methylation of tandem repeats. Environ. Mol. Mutagen. 55, 322-335. https://doi.org/10.1002/em.21838

He, X., Wang, L., Zhu, L., Yuan, D., He, Y., Jin, T. (2018). A case-control study of the genetic polymorphism of IL6 and HAPE risk in a Chinese Han population. Clin. Respir. J. 12, 2419-2425. https://doi.org/10.1111/crj.12922

He, Y., Liu, L., Xu, P., He, N., Yuan, D., Kang, L., Jin, T. (2017). Association between single nucleotide polymorphisms in ADRB2, GNB3 and GSTP1 genes and high-altitude pulmonary edema (HAPE) in the Chinese Han population. Oncotarget 8, 18206-18212. https://doi.org/10.18632/oncota rget.15309

Heidari, M.M., Mirfakhradini, F.S., Tayefi, F., Ghorbani, S., Khatami, M., Hadadzadeh, M. (2020). Novel Point Mutations in Mitochondrial $\mathrm{MT}-\mathrm{CO}_{2}$ Gene May Be Risk Factors for Coronary Artery Disease. Appl. Biochem. Biotechnol. 191, 1326-1339. https://doi.org/10.1007/s12010-02003275-0

Hu, Q., Wood, C.R., Cimen, S., Venkatachalam, A.B., Alwayn, I.P. (2015). Mitochondrial damageassociated molecular patterns (MTDs) are released during hepatic ischemia reperfusion and induce inflammatory responses. PLoS One 10, e0140105. https://doi.org/10.1371/journal.pon e.0140105

Iske, J., Seyda, M., Heinbokel, T., Maenosono, R., Minami, K., Nian, Y., Quante, M., Falk, C.S., Azuma, H., Martin, F., Passos, J.F., Niemann, C.U., Tchkonia, T., Kirkland, J.L., Elkhal, A., Tullius, S.G. (2020). Senolytics prevent mt-DNA-induced inflammation and promote the survival of aged organs following transplantation. Nat. Commun. 11, 4289. https://doi.org/10.1038/s41467020-18039-x

Jin, T., Zhu, L., Bai, M., He, X., Wang, L., Yuan, D., Li, S., He, Y. (2019). Association between the IL1R2 rs2072472 polymorphism and high-altitude pulmonary edema risk. Mol. Genet. Genomic Med. 7, e542. https://doi.org/10.1002/mgg3.542

Jing, R., Hu, Z.K., Lin, F., He, S., Zhang, S.S., Ge, W.Y., Dai, H.J., Du, X.K., Lin, J.Y., Pan, L.H. (2020). Mitophagy-mediated mtDNA release aggravates stretching-induced inflammation and lung epithelial cell injury via the TLR9/MyD88/NF-kappaB pathway. Front. Cell. Dev. Biol. 8, 819. https://doi.org/10.3389/fcell.2020.00819

Jirtle, R.L., Skinner, M.K. (2007). Environmental epigenomics and disease susceptibility. Nat. Rev. Genet. 8, 253-262. https://doi.org/10.1038/nrg2045

Lefrancais, E., Ortiz-Munoz, G., Caudrillier, A., Mallavia, B., Liu, F., Sayah, D.M., Thornton, E.E., Headley, M.B., David, T., Coughlin, S.R., Krummel, M.F., Leavitt, A.D., Passegue, E., Looney, M.R. (2017). The lung is a site of platelet biogenesis and a reservoir for haematopoietic progenitors. Nature 544, 105-109. https://doi.org/10.1038/nature21706

Li, N., Chen, J., Wang, P., Fan, H., Hou, S., Gong, Y. (2021). Major signaling pathways and key mediators of macrophages in acute kidney injury (Review). Mol. Med. Rep. 23, 455. https://doi.org/10.3892/mmr.2021.12094 
Liu, C.X., Tan, Y.R., Xiang, Y., Liu, C., Liu, X.A., Qin, X.Q. (2018). Hydrogen sulfide protects against chemical hypoxia-induced injury via attenuation of ROS-mediated $\mathrm{Ca}(2+)$ overload and mitochondrial dysfunction in human bronchial epithelial Cells. Biomed. Res. Int. 2018, 2070971. https://doi.org/10.1155/2018/2070971

Ma, W., Karakas, D., Chen, Z.Y., Ni, H. (2020). Aging, chronic inflammation, and platelet hyperactivity. Ann. Blood 5, 1-4. http://doi.org/10.21037/aob-20-32

Mariero, L.H., Torp, M.K., Heiestad, C.M., Baysa, A., Li, Y., Valen, G., Vaage, J., Stenslokken, K.O. (2019). Inhibiting nucleolin reduces inflammation induced by mitochondrial DNA in cardiomyocytes exposed to hypoxia and reoxygenation. Br. J. Pharmacol. 176, 4360-4372. https://doi.org/10.1111/bph.14830

McElroy, G.S., Chandel, N.S. (2017). Mitochondria control acute and chronic responses to hypoxia. Exp. Cell. Res. 356, 217-222. https://doi.org/10.1016/j.yexcr.2017.03.034

Michelakis, E.D., Thebaud, B., Weir, E.K., Archer, S.L. (2004). Hypoxic pulmonary vasoconstriction: Redox regulation of $\mathrm{O}_{2}$-sensitive $\mathrm{K}^{+}$channels by a mitochondrial $\mathrm{O}_{2}$-sensor in resistance artery smooth muscle cells. J. Mol. Cell Cardiol. 37, 1119-1136. https://doi.org/10.1016/j.yjmcc.200 4.09.007

Mills, E.L., Kelly, B., O'Neill, L.A.J. (2017). Mitochondria are the powerhouses of immunity. Nat. Immunol. 18, 488-498. https://doi.org/10.1038/ni.3704

Ortiz-Prado, E., Dunn, J.F., Vasconez, J., Castillo, D., Viscor, G. (2019). Partial pressure of oxygen in the human body: A general review. Am. J. Blood Res. 9, 1-14.

Pandey, P., Ali, Z., Mohammad, G., Pasha, M.A. (2016). Elevated blood plasma levels of epinephrine, norepinephrine, tyrosine hydroxylase, TGFbeta1, and TNFalpha associated with high-altitude pulmonary edema in an Indian population. Ther. Clin. Risk. Manage. 12, 12071221. https://doi.org/10.2147/TCRM.S111030

Parati, G., Agostoni, P., Basnyat, B., Bilo, G., Brugger, H., Coca, A., Festi, L., Giardini, G., Lironcurti, A., Luks, A.M., Maggiorini, M., Modesti, P.A., Swenson, E.R., Williams, B., Bärtsch, P., Torlasco, C. (2018). Clinical recommendations for high altitude exposure of individuals with pre-existing cardiovascular conditions. Eur. Heart J. 39, 1546-1554. https://doi.org/10.1093/eurheartj/ehx 720

Peng, Q., Li, J., Wang, Y., Zhao, L., Tan, J., He, C. (2021). Temporal and spatial distribution characteristics of $\mathrm{NO}_{\mathrm{x}}$ emissions of city buses on real road based on spatial autocorrelation. Aerosol Air Qual. Res. 21, 200059. https://doi.org/10.4209/aaqr.200059

Perez-Santiago, J., De Oliveira, M.F., Var, S.R., Day, T.R.C., Woods, S.P., Gianella, S., Mehta, S.R. (2017). Increased cell-free mitochondrial DNA is a marker of ongoing inflammation and better neurocognitive function in virologically suppressed HIV-infected individuals. J. Neurovirol. 23, 283-289. https://doi.org/10.1007/s13365-016-0497-5

Sanyal, T., Bhattacharjee, P., Bhattacharjee, S., Bhattacharjee, P. (2018). Hypomethylation of mitochondrial D-loop and ND6 with increased mitochondrial DNA copy number in the arsenicexposed population. Toxicology 408, 54-61. https://doi.org/10.1016/j.tox.2018.06.012

Sharma, N., Pasala, M.S., Prakash, A. (2019). Mitochondrial DNA: Epigenetics and environment. Environ. Mol. Mutagen. 60, 668-682. https://doi.org/10.1002/em.22319

Sharma, P., Sampath, H. (2019). Mitochondrial DNA integrity: Role in health and disease. Cells 8, 100. https://doi.org/10.3390/cells8020100

Singer, B.D. (2019). A practical guide to the measurement and analysis of DNA methylation. Am. J. Respir. Cell. Mol. Biol. 61, 417-428. https://doi.org/10.1165/rcmb.2019-0150TR

Sitko, S., Cirer-Sastre, R., Lopez Laval, I. (2019). Effects of high altitude mountaineering on body composition: A systematic review. Nutr. Hosp. 36, 1189-1195. https://doi.org/10.20960/nh.02 582

Sledz, K.M., Moore, S.F., Durrant, T.N., Blair, T.A., Hunter, R.W., Hers, I. (2020). Rapamycin restrains platelet procoagulant responses via FKBP-mediated protection of mitochondrial integrity. Biochem. Pharmacol. 177, 113975. https://doi.org/10.1016/j.bcp.2020.113975

Smith, K.M., Mrozek, J.D., Simonton, S.C., Bing, D.R., Meyers, P.A., Connett, J.E., Mammel, M.C. (1997). Prolonged partial liquid ventilation using conventional and high-frequency ventilatory techniques: Gas exchange and lung pathology in an animal model of respiratory distress syndrome. Crit. Care. Med. 25, 1888-1897. https://doi.org/10.1097/00003246-19971100000030 
Solaimanzadeh, I. (2020). Acetazolamide, nifedipine and phosphodiesterase inhibitors: Rationale for their utilization as adjunctive countermeasures in the treatment of coronavirus disease 2019 (COVID-19). Cureus 12, e7343. https://doi.org/10.7759/cureus.7343

Sreeramkumar, V., Adrover, J.M., Ballesteros, I., Cuartero, M.I., Rossaint, J., Bilbao, I., Nacher, M., Pitaval, C., Radovanovic, I., Fukui, Y., McEver, R.P., Filippi, M.D., Lizasoain, I., Ruiz-Cabello, J., Zarbock, A., Moro, M.A., Hidalgo, A. (2014). Neutrophils scan for activated platelets to initiate inflammation. Science 346, 1234-1238. https://doi.org/10.1126/science.1256478

Sun, X., Wang, Z., Cong, X., Lv, Y., Li, Z., Rong, L., Yang, T., Yu, D. (2021). Mitochondrial gene COX methylation and downregulation is a biomarker of aging in heart mesenchymal stem cells. Int. J. Mol. Med. 47, 161-170. https://doi.org/10.3892/ijmm.2020.4799

Swenson, E.R. (2020). Early hours in the development of high-altitude pulmonary edema: Time course and mechanisms. J. Appl. Physiol. 128, 1539-1546. https://doi.org/10.1152/japplphysi ol.00824.2019

Tao, D.L., Tassi Yunga, S., Williams, C.D., McCarty, O.J.T. (2021). Aspirin and antiplatelet treatments in cancer. Blood 137, 3201-3211. https://doi.org/10.1182/blood.2019003977

Ten, V.S., Ratner, V. (2020). Mitochondrial bioenergetics and pulmonary dysfunction: Current progress and future directions. Paediatr. Respir. Rev. 34, 37-45. https://doi.org/10.1016/j.prrv. 2019.04.001

Timon-Gomez, A., Nyvltova, E., Abriata, L.A., Vila, A.J., Hosler, J., Barrientos, A. (2018). Mitochondrial cytochrome c oxidase biogenesis: Recent developments. Semin. Cell. Dev. Biol. 76, 163-178. https://doi.org/10.1016/j.semcdb.2017.08.055

Wang, L., Wu, Q., Fan, Z., Xie, R., Wang, Z., Lu, Y. (2017). Platelet mitochondrial dysfunction and the correlation with human diseases. Biochem. Soc. Trans. 45, 1213-1223. https://doi.org/10. 1042/BST20170291

Witt, K.E., Huerta-Sanchez, E. (2019). Convergent evolution in human and domesticate adaptation to high-altitude environments. Philos. Trans. R. Soc. London, Ser. B 374, 20180235. https://doi.org/10.1098/rstb.2018.0235

Wu, X., Kong, Q., Zhan, L., Qiu, Z., Huang, Q., Song, X. (2019). TIPE2 ameliorates lipopolysaccharide-induced apoptosis and inflammation in acute lung injury. Inflamm. Res. 68, 981-992. https://doi.org/10.1007/s00011-019-01280-6

Xiang, F., Ma, S.Y., Zhang, D.X., Zhang, Q., Huang, Y.S. (2016). Tumor necrosis factor receptorassociated protein 1 improves hypoxia-impaired energy production in cardiomyocytes through increasing activity of cytochrome c oxidase subunit II. Int. J. Biochem. Cell Biol. 79, 239-248. https://doi.org/10.1016/j.biocel.2016.08.041

Xiang, F., Ma, S.Y., Lv, Y.L., Zhang, D.X., Song, H.P., Huang, Y.S. (2019). Tumor necrosis factor receptor-associated protein 1 regulates hypoxia-induced apoptosis through a mitochondriadependent pathway mediated by cytochrome c oxidase subunit II. Burns. Trauma. 7, 16. https://doi.org/10.1186/s41038-019-0154-3

Xu, Y., Li, H., Hedmer, M., Hossain, M.B., Tinnerberg, H., Broberg, K., Albin, M. (2017). Occupational exposure to particles and mitochondrial DNA - relevance for blood pressure. Environ. Health 16, 22. https://doi.org/10.1186/s12940-017-0234-4

Yang, L., Xia, B., Yang, X., Ding, H., Wu, D., Zhang, H., Jiang, G., Liu, J., Zhuang, Z. (2016). Mitochondrial DNA hypomethylation in chrome plating workers. Toxicol. Lett. 243, 1-6. https://doi.org/10.1016/j.toxlet.2015.11.031

Yang, M., Chen, P., Peng, H., Zhang, H., Chen, Y., Cai, S., Lu, Q., Guan, C. (2015). Cigarette smoke extract induces aberrant cytochrome-c oxidase subunit II methylation and apoptosis in human umbilical vascular endothelial cells. Am. J. Physiol. Cell Physiol. 308, C378-C384. https://doi.org/10.1152/ajpcell.00197.2014

Yin, X., de Foy, B., Wu, K., Feng, C., Kang, S., Zhang, Q. (2019). Gaseous and particulate pollutants in Lhasa, Tibet during 2013-2017: Spatial variability, temporal variations and implications. Environ. Pollut. 253, 68-77. https://doi.org/10.1016/j.envpol.2019.06.113

Zhang, H., Chen, P., Zeng, H., Zhang, Y., Peng, H., Chen, Y., He, Z. (2013). Protective effect of demethylation treatment on cigarette smoke extract-induced mouse emphysema model. J. Pharmacol. Sci. 123, 159-166. https://doi.org/10.1254/jphs.13072fp

Zhang, J.L., Li, X.Y. (2015). A review of drug metabolism under hypoxia environment at high altitude. Yao Xue Xue Bao 50, 1073-1079. 
Zhang, S., Liu, J., Jiang, D., Wuren, T., Ma, S., Du, Y., Yi, X., Wu, S. (2018). The plasma level changes of VEGF and soluble VEGF receptor-1 are associated with high-altitude pulmonary edema. J. Med. Invest. 65, 64-68. https://doi.org/10.2152/jmi.65.64

Zhang, Y., Cai, Y.J., Yu, F., Luo, G., Chou, C.C.K. (2021). Seasonal variations and long-term trend of mineral dust aerosols over the Taiwan region. Aerosol Air Qual. Res. 21, 200433. https://doi.org/10.4209/aaqr.2020.07.0433

Zhao, M., Wang, Y., Li, L., Liu, S., Wang, C., Yuan, Y., Yang, G., Chen, Y., Cheng, J., Lu, Y., Liu, J. (2021). Mitochondrial ROS promote mitochondrial dysfunction and inflammation in ischemic acute kidney injury by disrupting TFAM-mediated mtDNA maintenance. Theranostics 11, 1845-1863. https://doi.org/10.7150/thno.50905

Zhou, Q., Wang, D., Liu, Y., Yang, X., Lucas, R., Fischer, B. (2017). Solnatide demonstrates profound therapeutic activity in a rat model of pulmonary edema induced by acute hypobaric hypoxia and exercise. Chest 151, 658-667. https://doi.org/10.1016/j.chest.2016.10.030 